\title{
Seismological constraints on the density, thickness and temperature of the lithospheric mantle in southwestern Tibet
}

\author{
Harry Matchette-Downes ${ }^{\mathrm{a}}$, Robert D. van der Hilst ${ }^{\mathrm{a}}$, Amy Gilligan ${ }^{\mathrm{b}}$, Keith \\ Priestley $^{\mathrm{c}}$ \\ ${ }^{a}$ Department of Earth, Atmospheric and Planetary Sciences, Massachusetts Institute of \\ Technology, U.S.A. \\ ${ }^{b}$ School of Geosciences, University of Aberdeen, U.K. \\ ${ }^{c}$ Bullard Laboratories, University of Cambridge, U.K.
}

\begin{abstract}
We constrain the lithospheric mantle in southwest Tibet to be cold, thick, and dense by considering seismological observations, isostasy, and gravity anomalies. First, virtual deep seismic sounding (VDSS) indicates that the thickness of the crust increases from $50 \pm 4 \mathrm{~km}$ beneath the Himalaya to $70 \pm 4 \mathrm{~km}$ in the Lhasa terrane. This implies a 'residual topography' (difference between isostatic elevation of crust and true elevation) of $-2.4 \pm 1.5 \mathrm{~km}$. Taking into account deviations from isostasy, the lithospheric mantle must be dense enough to depress the surface by 0.9 to $4.5 \mathrm{~km}$. Our joint inversion of fundamental-mode Rayleigh wave dispersion and receiver functions suggests that the verticallypolarised shear-wave speed $\left(V_{s v}\right)$ is $4.6 \pm 0.1 \mathrm{~km} \mathrm{~s}^{-1}$ at depths of 120 to $300 \mathrm{~km}$. From the shear-wave speed profile, we estimate the geotherm, which is on average $200{ }^{\circ} \mathrm{C}$ below the $1350{ }^{\circ} \mathrm{C}$ adiabat, and suggest that the base of the lithosphere is at a depth of $290 \pm 30 \mathrm{~km}$. To match the negative buoyancy, the lithospheric must be denser, on average, than 'normal' fertile adiabatic mantle, which rules out a depleted (harzburgite) composition. The density excess can be explained solely by thermal contraction, but we cannot rule out additional density increases due to composition. Our observations are not consistent with a depleted Indian slab underthrusting Tibet in this region, which would result in a lower average density and lower temperatures.
\end{abstract}

Draft in revision for Earth and Planetary Science Letters

July 12, 2019 
Keywords: Tibet, isostasy, lithosphere, density, mantle, seismology

\section{Introduction}

This work presents constraints on the state of the upper mantle in southwestern Tibet, in particular its shear-wave speed and density, and inferences about its temperature, thickness, composition and contribution to the topography. These constraints, as part of a larger view of the whole Plateau, could help to test hypotheses about processes which occur during continent-continent collisions, for example convective instability (e.g. England and Houseman, 1989), delamination (Bird, 1978), cratonisation (e.g. McKenzie and Priestley, 2016), and changes in climate due the varying height of the Plateau (e.g. Molnar et al. 2010).

Previous tomographic studies of the entire Plateau agree that seismic waves propagate quickly through the upper mantle in western Tibet, whether they be surface waves (e.g. Priestley et al., 2006)), P-waves (Li et al., 2008, Zhao et al., 2014, e.g.) or $\mathrm{S}_{n}$ waves (Barron and Priestley, 2009). High wavespeeds indicate a thick, cold lithosphere root, which might represent a slab of Indian lithosphere being thrust beneath Tibet, or the thickened lithosphere of Tibet (e.g. Molnar et al. 1993). To investigate these structures at a finer scale, we use data from the U.S.-China Array (Razi et al., 2014), shown in figure 1. The network was active from 2007 to 2011, with between 7 and 30 stations operating in a 300-km-by-300-km region. Previous studies of the upper mantle using this dataset include the body-wave tomography of Razi et al. (2014, 2016). They interpreted a complicated pattern of high-wavespeed anomalies as the products of the Indian lithospheric slab being thrust beneath Tibet: eclogite, drips, and delamination. For our own study of the mantle, we build on the work of Gilligan et al. (2015), who calculated receiver functions and fundamental-mode Rayleighwave group-speed dispersion. They inverted these observations to determine the three-dimensional shear-wave speed variations and thickness of the crust. We incorporate the same dispersion curves and receiver functions in our study. 


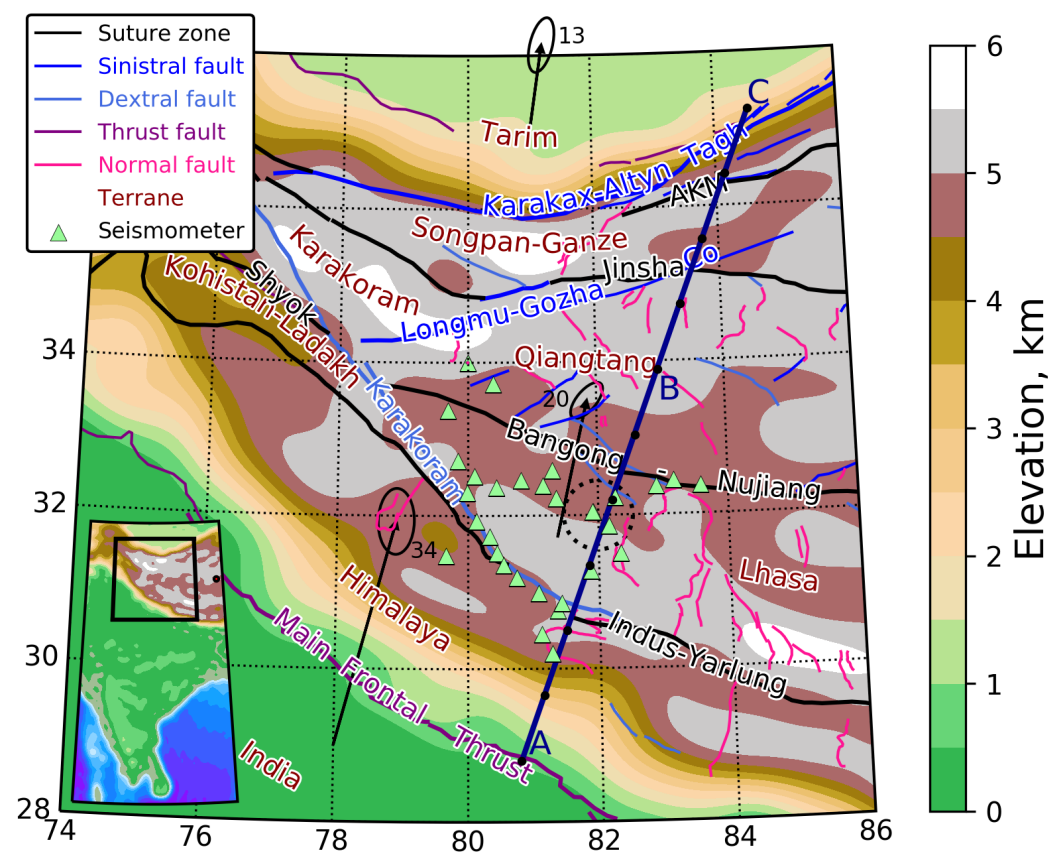

Figure 1: A map of western Tibet which shows smoothed topography, major tectonic blocks and lineaments, and the network of seismometers, as indicated in the legend. The dark blue line indicates the cross-section through points $\mathrm{A}, \mathrm{B}$ and $\mathrm{C}$ used in later figures, with black marker circles at intervals of $100 \mathrm{~km}$. Tectonic plate velocities relative to stable Eurasia are shown for India, western Tibet and the Tarim block (Gan et al., 2007) are shown as black arrows with one-standard-deviation uncertainty ellipses and labelled with the velocity in $\mathrm{mma}^{-1}$. The topography was filtered by truncating a spherical harmonic expansion of the SRTM (Shuttle Radar Topography Mission) global digital elevation model at an angular order of 300 , corresponding to a minimum wavelength of around $130 \mathrm{~km}$. Tectonic lineaments are from the HimaTibetMap database (Styron et al. 2010). The abbreviation 'AKM' is for the Anyimaqen-Kunlun-Muztagh suture. The coordinates of the cross-section points are A: $\left(80.800^{\circ} \mathrm{E}, 28.800^{\circ} \mathrm{N}\right)$; B: $\left(82.915^{\circ} \mathrm{E}, 33.867^{\circ} \mathrm{N}\right) ; \mathrm{C}:\left(84.541^{\circ} \mathrm{E}, 37.219^{\circ} \mathrm{N}\right)$. 


\section{Methods}

\subsection{Inversion for phase speed}

We used the two-plane-wave inversion of Forsyth and $\mathrm{Li}(2005)$ with realistic sensitivity kernels (Yang and Forsyth, 2006b) to map the local phase speed in 11 frequency bands, with periods from 20 to 143 seconds. The input data were the amplitude and phase of the windowed fundamental-mode Rayleigh wave (figure 2 a,b), measured with a Fourier transform.

We searched the ANSS (Advanced National Seismic System) Comprehensive Earthquake Catalogue for teleseismic events closer than $120^{\circ}$ with moment magnitude of at least 6 . For each event, the inversion requires at least four stations which record surface waves with sufficiently high signal-to-noise ratio. After inspection, 550 events met this criterion. From these, a subset of 108 events was chosen to maximise the ray coverage while preserving a relatively uniform azimuthal distribution, which reduces bias in the inversion (Bodin and Maupin, 2008). The selected events and ray coverage are shown in figure 2 .

\subsection{Inversion for shear-wave speed and temperature estimation}

The inverse problem was solved using simulated annealing with smoothing regularisation. Starting with a uniform model, we solve for a profile with six layers over 50 annealing steps. This coarse model is used as the input to a second iteration with 31 layers over 150 annealing steps. In each case, the base of the model is at a depth of $300 \mathrm{~km}$. The results were not sensitive to the uniform wavespeed used as a starting model, within a reasonable range of 4 to $6 \mathrm{~km} \mathrm{~s}^{-1}$. Forward calculation of synthetic receiver functions and dispersion curves was done using trftn96 and sdisp96, respectively, both from the CPS package (Herrmann, 2013). We fixed the $V_{p} / V_{s}$ ratio to 1.75 based on the study of Murodov et al. (2018), which used the $H-\kappa$ stacking method (Zhu and Kanamori, 2000) to find values between 1.7 and 1.8 on the eastern edge of our study region.

The one-dimensional profiles were then combined into a three-dimensional model by interpolation. By solving for one-dimensional profiles, we assume 

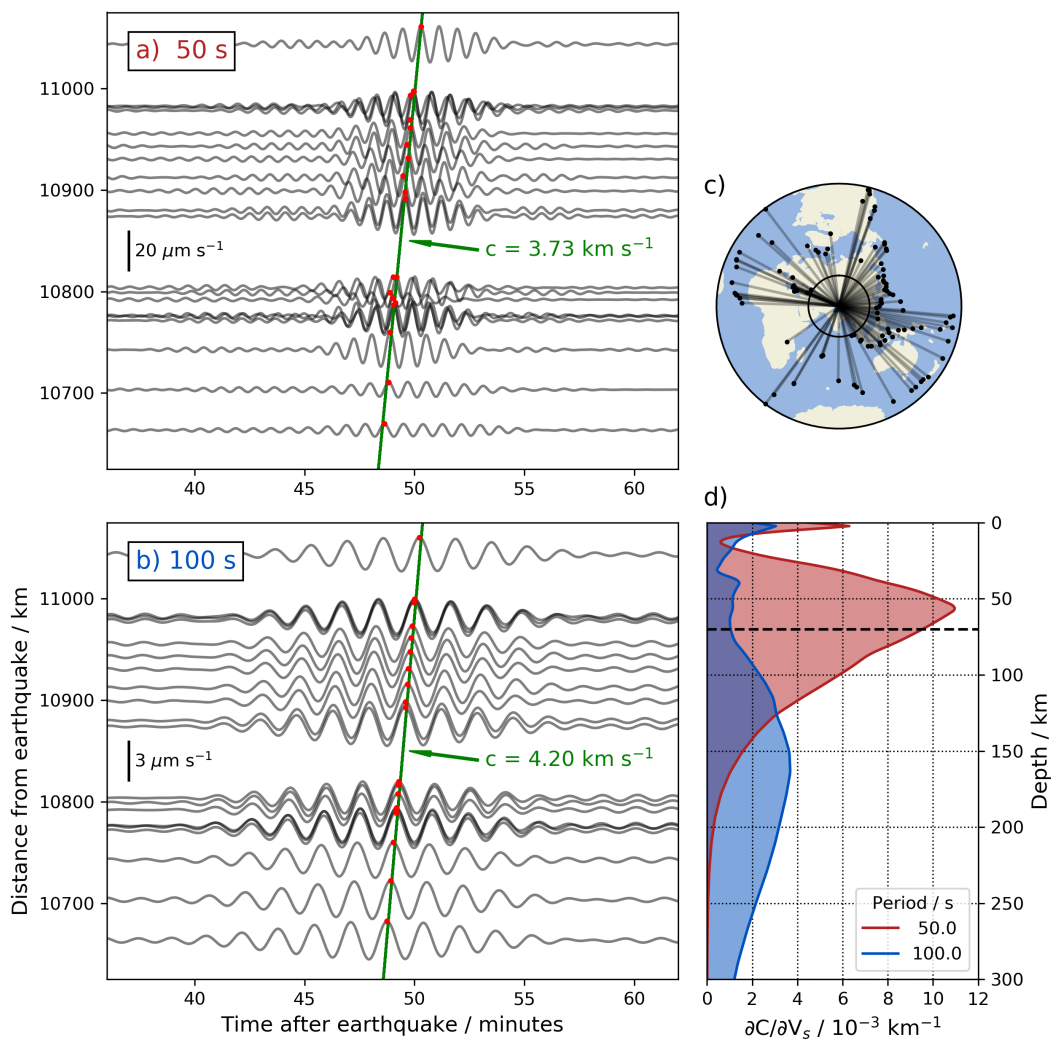

Figure 2: Summary of input data for inversion of Rayleigh-wave phase speed. Panels a) and b) show the same record section of vertical-component velocity seismograms, windowed around the Rayleigh wave, after application of bandpass filters with central periods of 50 and $100 \mathrm{~s}$ respectively. In each case, a representative phase velocity is indicated by a green line, passing through points of constant phase (red dots). The amplitude of seismograms is indicated by a black scale bar. Panel c) shows the distribution of earthquake events used in the inversion, using an azimuthal equidistant projection centred on the network. The inner and outer circles are at epicentral distances of $30^{\circ}$ and $120^{\circ}$, respectively. Not all pairs of events and stations yielded input data in all frequency bands, as shown in the ray coverage diagrams (supplementary figure 11. Panel d) shows the sensitivity of the Rayleigh-wave phase speed to shear-wave speed for the two frequencies shown in panels a) and b), based on the average Earth model shown in figure 6 The base of the crust is depicted by a dotted black line. 
that lateral variations in wavespeed are smooth relative to the wavelength. We mitigate the bias due to this assumption by using azimuthally-binned receiver functions and an even distribution of surface wave sources (figure 2 ;).

\subsection{Estimation of temperature and density from shear-wave speed}

From the shear-wave speed profile, we estimated the temperature as a function of depth (geotherm) of the upper mantle using the relationship between shear-wave speed, temperature, and pressure developed by Priestley and McKenzie (2006) and refined in Priestley and McKenzie (2013). In this method, a global tomographic model of shear-wave speed is calibrated against temperature and depth measurements estimates from oceanic plate cooling models and xenoliths derived from the mantle lithosphere. We do not apply the method to the crust, where the calibration would not be valid.

After obtaining temperature estimates, we converted these to temperature anomalies relative to a reference adiabatic mantle geotherm with a potential temperature of $1350^{\circ} \mathrm{C}$. The temperature anomalies were then related to density anomalies by assuming a constant coefficient of thermal expansion of $3 \times 10^{-5}{ }^{\circ} \mathrm{C}^{-1}$.

\subsection{Crust thickness from virtual deep seismic sounding}

We estimated the thickness of the crust using virtual deep seismic sounding, a method described in detail in Tseng et al. (2009) and Yu et al. (2012). For this technique, we observe the time difference between the direct $\mathrm{S}$ wave and the Moho reflection of the free-surface S-to-P converted wave (the SsPmp phase), as shown in the ray diagram and seismograms in figure 3 . For the simple Earth model with a single crust layer over a mantle half-space, the time delay is proportional to the crust thickness, $H$, as given by:

$$
T=2 H \sqrt{V_{p}^{-2}-p_{\beta}^{2}}
$$

where $V_{p}$ is the average $\mathrm{P}$-wave speed in the crust, and $p_{\beta}$ is the ray parameter (horizontal slowness) of the incident $\mathrm{S}$ wave. In practice, the reflection causes phase shifts, so instead of picking the $S s$ and $S s P m p$ phases it is necessary to 
fit the two arrivals with a synthetic seismogram calculated from a given Earth model; here we use a simple model with two layers: crust and mantle. The parameters of these layers are discussed in section 2.5. The seismograms are synthesised using the reflection matrix method (Kennett, 1974) as implemented in the respknt program (Randall, 1994).

The best-fitting crust thickness corresponds to the highest cross-correlation between the real and synthetic seismograms. We fit both the vertical and radial components, although the vertical component is given $50 \%$ more weight (after amplitude normalisation), because it is typically less noisy. The post-critical reflection is strong and does not require stacking, even if the crust-mantle transition is gradual, as seems to be the case in western Tibet (Gilligan et al., 2015). It is also relatively immune to other complications such as mid-crust structures and sediment reverberations (Yu et al. 2016).

The arrival time of the $S s P m p$ pulse can usually be measured to within $0.4 \mathrm{~s}$, corresponding to an uncertainty in crust thickness of only $2 \mathrm{~km}$, despite instrumental noise, contamination by other converted phases, and broadening of the pulses by complex crust structure. However, we find that nearby estimates of crust thickness have a higher standard deviation of $4 \mathrm{~km}$, which we attribute to variations in structure along different incident ray paths. To account for this during propagation of uncertainty, we assume that the standard deviation in $T$ is correspondingly increased to $0.8 \mathrm{~s}$.

We searched the ANSS Comprehensive Earthquake Catalogue again, this time for large $\left(M_{w}>5.5\right)$ earthquakes with epicentral distances between 30 and $55^{\circ}$, which are sufficiently distant to avoid triplications, but close enough to have a post-critical $S s P m p$ phase. We visually inspected seismograms for all earthquakes occurring below a depth of $100 \mathrm{~km}$, as they are most likely to have the simple source-time functions necessary for our waveform fitting. We found just six suitable events, shown in figure $3 \mathrm{~b}$ and supplementary table 1. The events in the Moro Gulf are a mainshock-aftershock pair, and yield very similar results, which we averaged before interpretation. 


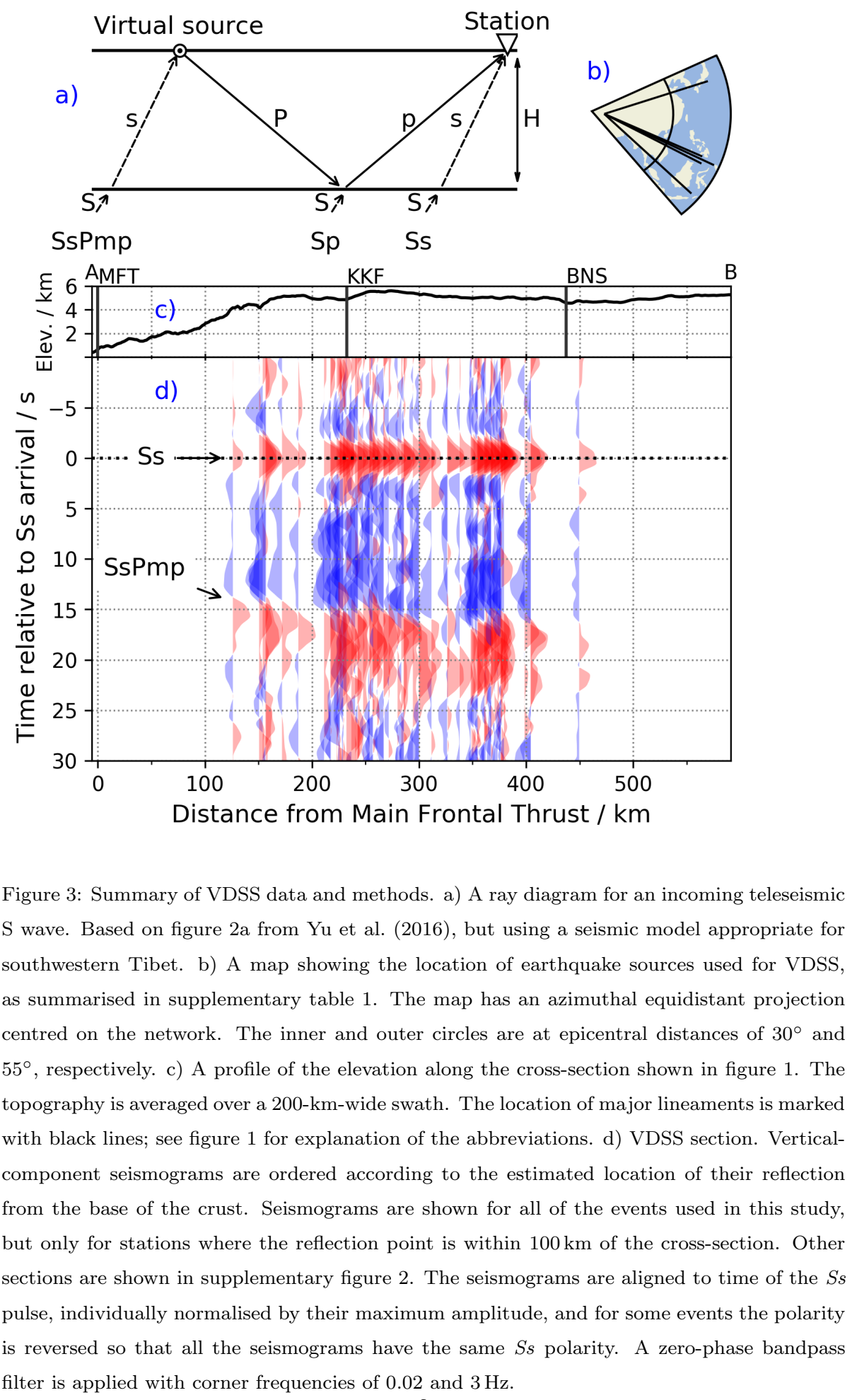




\subsection{Isostatic balance calculations}

Within Tibet, small free-air gravity anomalies at long wavelengths indicates isostatic equilibrium (e.g Turcotte and Schubert, 2014, section 5.12). Thus we can use the principal of isostasy to balance the mass per unit area in Tibet and at a reference point, which we choose to be a mid-ocean ridge, as shown in figure 4. However, in western Tibet, the free-air anomaly increases, reaching $30 \pm 20 \mathrm{mGal}$ in the region where we assume isostasy (supplementary figure 3). This would be expected around the edges of thick crust in isostatic equilibrium. However, this anomaly could also indicate that up to $600 \mathrm{~m}$ of the $5 \mathrm{~km}$ elevation is not isostatically compensated (e.g Molnar et al., 2015), but instead supported either by plate flexure or by vertical forces applied at the base of the lithosphere (as dynamic topography), or both. Therefore, we include a dynamic topography term $\epsilon_{d}$. With this addition, we can solve the vertical mass balance for the elevation of Tibet:

$\epsilon=\epsilon_{d}+\underbrace{\frac{\left(\rho_{s a}-\rho_{t c}\right)}{\rho_{s a}} H_{t c}}_{\epsilon_{i c}}+\underbrace{\frac{\left(\rho_{d a}-\rho_{t l m}\right)}{\rho_{s a}} H_{t l m}}_{\epsilon_{i l m}}-\underbrace{\left(\frac{\left(\rho_{s a}-\rho_{r w}\right)}{\rho_{s a}} H_{t w}+\frac{\left(\rho_{s a}-\rho_{r c}\right)}{\rho_{s a}} H_{r c}\right)}_{H_{r}}$

The variables are described in table 1 . Note that the distinction between 'shallow' and 'deep' asthenosphere in the reference model does not correspond to a particular lithological boundary, but a distinction between the part of the reference model where we must assume an absolute value of the density $\left(\rho_{s a}\right)$ and the part where we are only concerned with a density contrast $\left(\rho_{t l m}-\rho_{d a}\right)$.

The final term, $H_{r}$, comes from the mid-ocean ridge reference model, and corresponds to the height above sea level of an air-loaded column of density $\rho_{s a}$. We estimate that $H_{r}$ is $-2.6 \pm 0.4 \mathrm{~km}$ using values from table 1 .

The second term of the right-hand side of equation 2, $\epsilon_{i c}$, is the elevation due to the buoyancy of the Tibetan crust. We can estimate this using VDSS if we substitute the crust thickness $\left(H_{t c}\right)$ calculated with equation 1 .

$$
\epsilon_{i c}=\frac{\left(\rho_{s a}-\rho_{t c}\right)}{\rho_{s a}} \cdot \frac{T}{2\left(V_{p}^{-2}-p_{\beta}^{2}\right)^{1 / 2}}
$$


We estimate the density of the crust from the average P-wave speed reported by Razi et al. (2014) using the empirical Nafe-Drake relationship for crust rocks (Brocher, 2005). Consequently, the uncertainty in our estimate of crust buoyancy is reduced, because $\epsilon_{i c}$ depends only weakly on our choice of P-wave speed; for explicit calculations, see $\mathrm{Yu}$ et al. (2016, section 4.1).

The Nafe-Drake relationship is only approximately true, so during error propagation we assume that the crust density is given by the Nafe-Drake relationship plus additional noise with a standard deviation $50 \mathrm{~kg} \mathrm{~m}^{-3}$. This would correspond to a correlation coefficient of 0.40 between the density and wavespeed, which is a conservative choice; for example, if the correlation coefficient had the higher value of 0.88 , as observed in values reported by Christensen (1996, table 2), the uncertainty in the crust buoyancy would be further reduced.

In addition to the crust P-wave speed and density (discussed above), we must assume four additional parameters to model the $S s$ and $S s P m p$ phases: the S-wave speed in the crust, and the P-wave speed, S-wave speed, and density of the upper mantle. For the S-wave speed, we use average values of $3.5 \mathrm{~km} \mathrm{~s}^{-1}$ in the crust and $4.6 \mathrm{kms}^{-1}$ in the upper mantle, based on our tomographic model (see section 5). We assign a P-wave speed of $8.1 \mathrm{~km} \mathrm{~s}^{-1}$ to the upper mantle, as reported by Razi et al. (2014), and a density of $3200 \mathrm{~kg} \mathrm{~m}^{-3}$.

\subsection{Density of Tibet's mantle lithosphere}

We can rearrange equation 2 to solve for the average density contrast between Tibet's mantle lithosphere and the reference mantle (adiabatic mantle beneath a mid-ocean ridge), that is, $\Delta \rho=\rho_{t l m}-\rho_{d a}$. We can also estimate this density contrast from the geoid anomaly, $\Delta N$. To do this, we rearrange the standard expression for the geoid anomaly (e.g. Turcotte and Schubert, 2014, equation $5.145)$, as shown in the appendix. We present the mean of the two estimates, taking into account that they are not fully independent.

When using the geoid as a constraint, we first remove the long-wavelength component of the geoid by excluding terms with angular order below 20 (corresponding to wavelengths of $2000 \mathrm{~km}$ and longer) from the spherical harmonic 


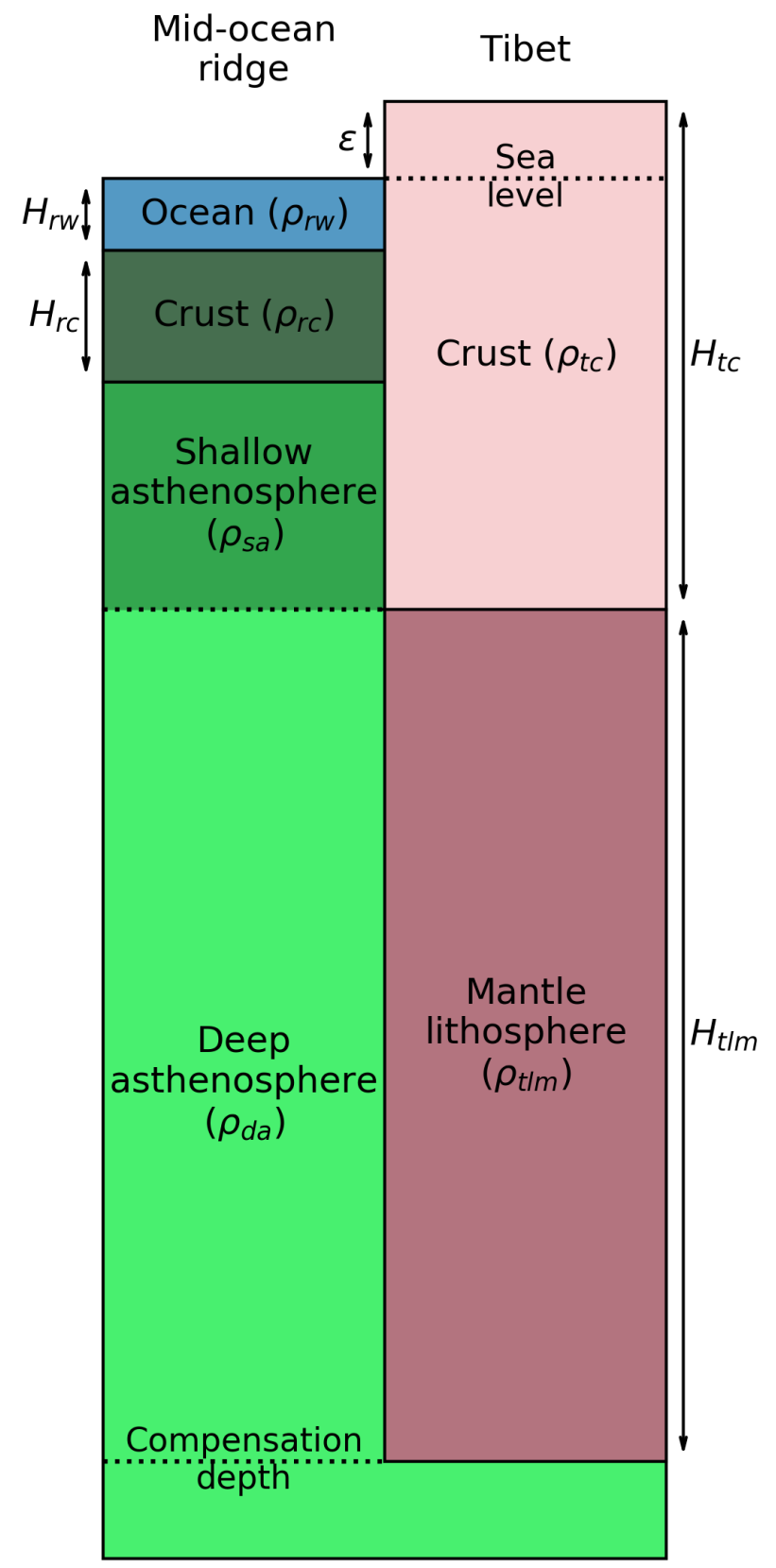

Figure 4: Models of Tibet and a mid-ocean ridge used for calculation of Tibet's isostatic elevation, $\epsilon$. Sections are labelled by their density $\rho$ and thickness $H$ which are explained in table 1 The layer thicknesses are not to scale. 


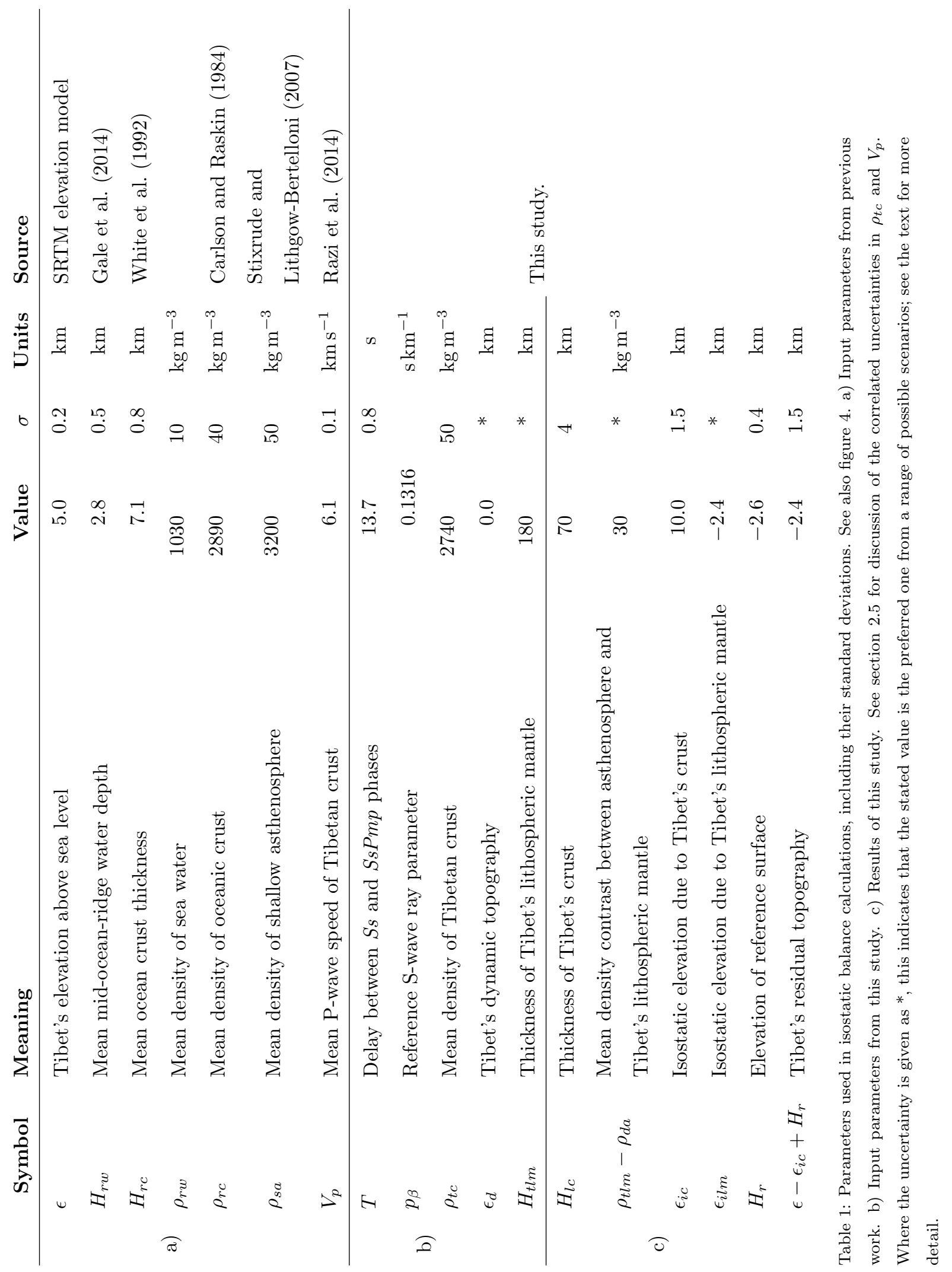


expansion. In our study area, the geoid anomaly is $8.2 \pm 0.4 \mathrm{~m}$ (Pavlis et al. 2012, and supplementary figure 4). Although this is well-constrained, we assign a larger uncertainty of $8 \pm 8 \mathrm{~m}$ when estimating the density contrast. This is to account for the unknown non-uniform mass distribution and deviations from isostasy.

\section{Results}

\subsection{Shear-wave speed}

The joint inversion is able to fit the phase- and group-speed dispersion and receiver functions within uncertainty bounds (e.g. supplementary figure 5). The resulting model of shear-wave speed is shown in colour in figure 5, which is a cross-section in a direction parallel to the convergence of India and Eurasia. Within the resolution of our data, the shear-wave-speed structure does not vary significantly across strike (as shown in supplementary figure 6). The crust model of Gilligan et al. (2015) is not substantially altered by including our phase-speed measurements. Specifically, the crust contains a continuous low-speed layer, dropping to about $3.2 \mathrm{~km} \mathrm{~s}^{-1}$ at depths between 25 and $40 \mathrm{~km}$, before a gradual transition to the mantle. The average vertically-polarised shear-wave speed in the crust is $3.5 \mathrm{~km} \mathrm{~s}^{-1}$.

In the upper mantle, the wavespeed differs between the Himalayas and the interior of Tibet. Down to a depth of $200 \mathrm{~km}$, the wavespeed is higher within the Plateau $\left(4.65 \mathrm{~km} \mathrm{~s}^{-1}\right.$ and $4.5 \mathrm{~km} \mathrm{~s}^{-1}$, respectively). This pattern is reversed at depths of 200 to $300 \mathrm{~km}$, where the wavespeeds are slightly higher beneath the Himalayas $\left(4.7 \mathrm{~km} \mathrm{~s}^{-1}\right.$ and $4.65 \mathrm{~km} \mathrm{~s}^{-1}$, respectively).

At these depths, the resolution is determined by the longer-period Rayleigh waves. The horizontal resolution at a given depth is roughly 2.5 times that depth. This is because two-plane-wave inversion can resolve phase speed variations on the scale of one wavelength (Yang and Forsyth, 2006a), and the wavelength of a Rayleigh wave is about 2.5 times the depth of peak sensitivity. Thus, in the upper mantle, we only expect to resolve features almost as large as the 

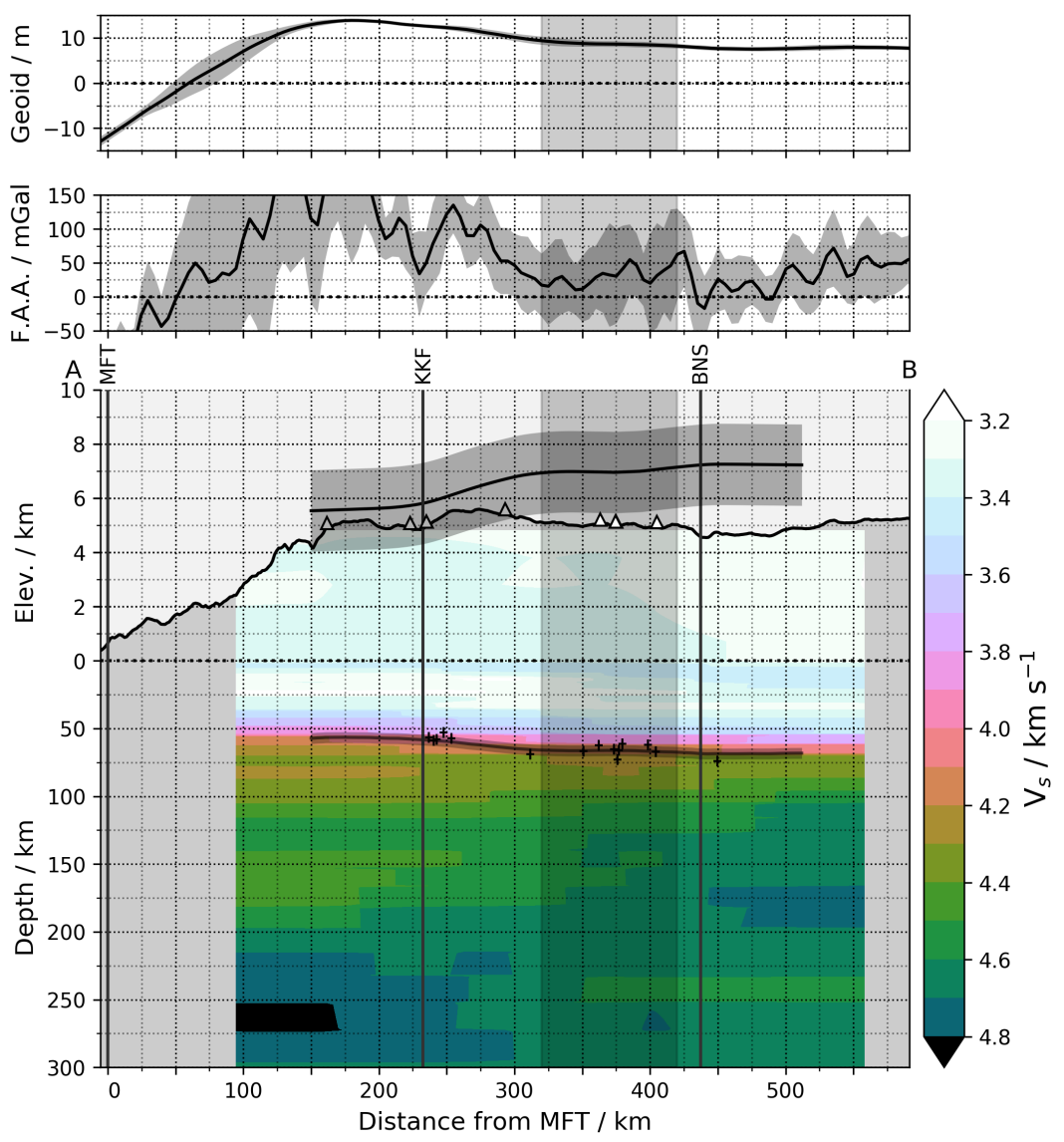

Figure 5: Cross-sections from A to B (see map, figure 1). Main panel: Cross-section through the models of shear-wave speed and crust thickness. The shear-wave speed model is shown in colour. Individual VDSS estimates of the crust thickness are shown as black crosses with error bars. (Only measurements within $30 \mathrm{~km}$ of the line are shown; see figure 8 ) These individual measurements are interpolated by the black line with a grey shaded error bars. Above sea level, the continuous black line shows the topography. This topographic profile is an average over a 200-km-wide swath and is vertically exaggerated by a factor of 20 . Overlying the topography is a black line with shaded error bars, which shows the elevation which would be expected from crust buoyancy, given the estimated crust thickness. Stations within $30 \mathrm{~km}$ of the profile are shown as white triangles. The grey vertical shaded region is the section used for isostatic balance calculations (shown in map view in figure 8). Black vertical lines mark the surface locations of the Main Frontal Thrust (MFT), Karakoram Fault (KKF) and BangongNujiang Suture (BNS). Upper panel: A profile of the EGM2008 geoid height model (Pavlis et al. 2012). Middle panel: A profile of the EGM2008 gravity free air anomaly (FAA) model (Pavlis et al. 2012) along the same line. For both the middle and upper panels, the profiles are averaged over a $200-\mathrm{km}$-wide swath with the shaded region indicating standard deviation across the swath. In both cases, the model extends to angular order 2159 , corresponding to a wavelength of around $20 \mathrm{~km}$. 
network, and below about $150 \mathrm{~km}$ (corresponding to periods longer than around $90 \mathrm{~s})$ the results will be dominated by the regional average.

Therefore, we base the following interpretation of isostatic balance on the average of $V_{s v}$ over all stations, which is shown in figure 6. The shear-wave speed is high: 4.5 to $4.7 \mathrm{~km} \mathrm{~s}^{-1}$ from depths of $120 \mathrm{~km}$ to the base of the model at $300 \mathrm{~km}$.

We also present a comparison with the model of shear-wave speed model of Priestley et al. (2018), which is a global model based on tomographic inversion of path-averaged wavespeed models obtained by cross-correlation of observed fundamental- and higher-mode Rayleigh wave with synthetic seismograms. The two models agree, except in the crust, where the model of Priestley et al. (2018) was fixed before the inversion.

\subsection{Mantle temperature, lithosphere thickness and compensation depth}

We convert our $V_{s v}$ profile to a temperature profile (figure 6) using the relationship discussed in section 2.3. From the base of the crust at $70 \mathrm{~km}$ to a depth of $300 \mathrm{~km}$, the temperature is on average $200{ }^{\circ} \mathrm{C}$ lower than the $1350{ }^{\circ} \mathrm{C}$ adiabat. This would suggest a density increase due to thermal contraction of around $20 \mathrm{~kg} \mathrm{~m}^{-3}$.

The base of the lithosphere was defined by Priestley and McKenzie (2006) as the depth at which the convecting (adiabatic) geotherm intersects the conductive geotherm. Our temperature profile (right panel of figure 6) suggests this is $290 \pm 30 \mathrm{~km}$ below the surface; equivalently, the lithospheric mantle is $225 \pm 30 \mathrm{~km}$ thick. However, this estimate should be interpreted cautiously, as conversions between shear wave speed and temperature are quite uncertain. This is due to factors such as grain size, melt and composition, which are not known for this region, and whose influence is not fully understood. Artemieva et al. (2004) estimate that a range of temperatures of $\pm 250^{\circ} \mathrm{C}$ can correspond to a given wave speed.

Uncertainties in the lithospheric thickness are relevant to our isostatic balance calculations because the contribution of the mantle lithosphere to the eleva- 

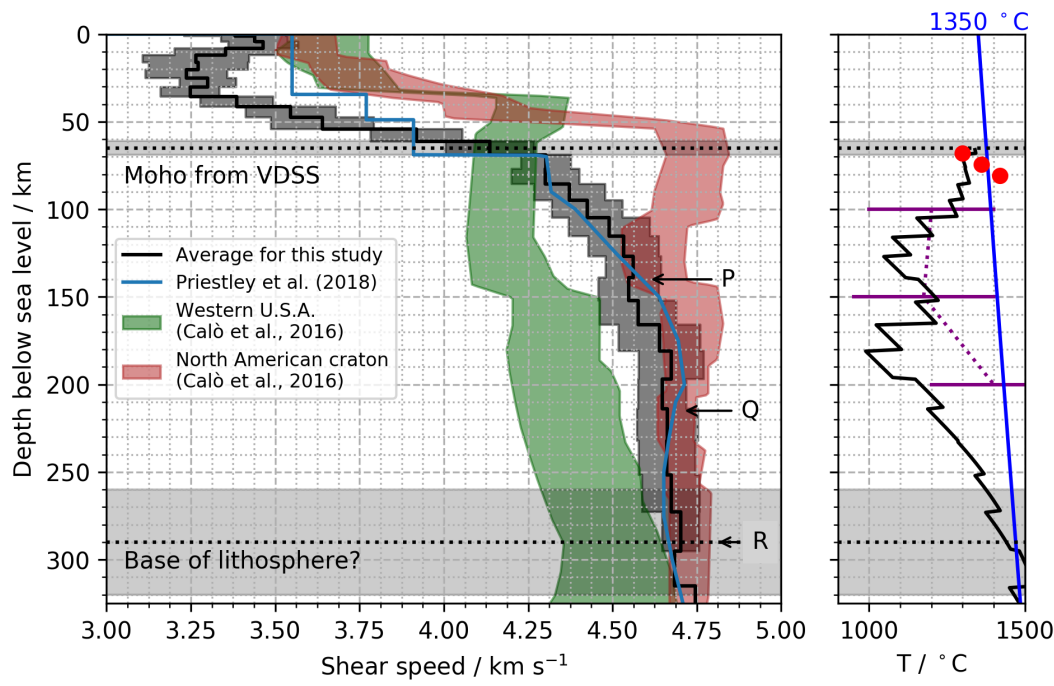

Figure 6: Left: A vertical profile of the average shear-wave speed for our model. Also shown are two North American reference models from Calò et al. (2016), and the model of Priestley et al. (2018), as shown in the legend. The shaded regions show one-standard-devation uncertainty estimates. Possible depths for the base of the lithosphere, based on the previous work shown in figure 7 are labelled as P, Q and R. They correspond to the values of lithospheric thickness shown in table 2 as discussed in the text. Right: A temperature profile estimated from the shear wave speed profile. An adiabatic geotherm with a potential temperature of $1350^{\circ} \mathrm{C}$ is shown in blue. The red dots indicate the temperature and pressure inferred from melting experiments on ultrapotassic rocks in the centre of the Qiangtang terrane Holbig and Grove 2008), for three assumed values of water content: $5 \mathrm{wt} \%, 2 \mathrm{wt} \%$, and $0 \mathrm{wt} \%$, in order from shallow to deep. The purple bars show the temperature model of An and Shi (2007). Discontinuities in the geotherm are due to the piecewise constant wavespeed model, and we expect that the true geotherm is smoother. 
tion is proportional to the product of its thickness and average density (equation 2). Various configurations of the Indian and Eurasian plates are compatible with our results and seismic sections from previous studies (figure 7). For example, if the Indian slab has thrust beneath Tibet but is no longer coupled to the Tibetan mantle lithosphere, the base of the lithosphere (and the compensation depth) might be as shallow as $140 \mathrm{~km}$ (figure $7 \mathrm{~b}$, dashed line), corresponding to a thickness of $75 \mathrm{~km}$. The decoupled Indian lithosphere would not contribute to the isostatic balance. Therefore, in the following calculation of isostasy, we test thicknesses of $75 \mathrm{~km}, 150 \mathrm{~km}$ and $225 \mathrm{~km}$ (cases P, Q and R in figures 6 and 7).

\subsection{Crust thickness from virtual deep seismic sounding}

Our waveform modelling, using a uniform crust layer, is able to fit the arrival time of almost all the $S s$ and $S s P m p$ phases for radial and vertical components simultaneously (supplementary figures 8 to 13 . This simplified approach does not fit the broadening of the $S s P m p$ pulse relative to to $S s$ pulse, or later arrivals, which are likely due to scattering by the complicated structures in the crust. In some cases, the fitted $S s P m p$ pulse has a smaller amplitude than the pbserved one, probably due to the neglected effects of shallow sediments (Liu et al. 2018).

A map of the crust thickness from the waveform fitting is shown in figure 8. Point-wise measurements are given at the reflection point at the base of the crust, and between these points estimates are made by kriging. The pattern of crust thickness does not closely follow the surface expression of the major lineaments. However, the major variations are roughly parallel to the strike of the system. The crust is only $50 \mathrm{~km}$ thick beneath the Himalaya and YarlungTsangpo Valley, while, moving across the Plateau (northeast), it increases to 65 to $75 \mathrm{~km}$ thick in the centre of the Lhasa Terrane. The thickest crust, up to $80 \mathrm{~km}$ thick, is found in the Qiangtang Terrane in the extreme north of the study region. In the northeastern part of the study area, the crust thins to 65 to $70 \mathrm{~km}$. The crust thickness used for isostatic balance calculations was $70 \pm 4 \mathrm{~km}$, calculated from the point-wise measurements in the circled region of 


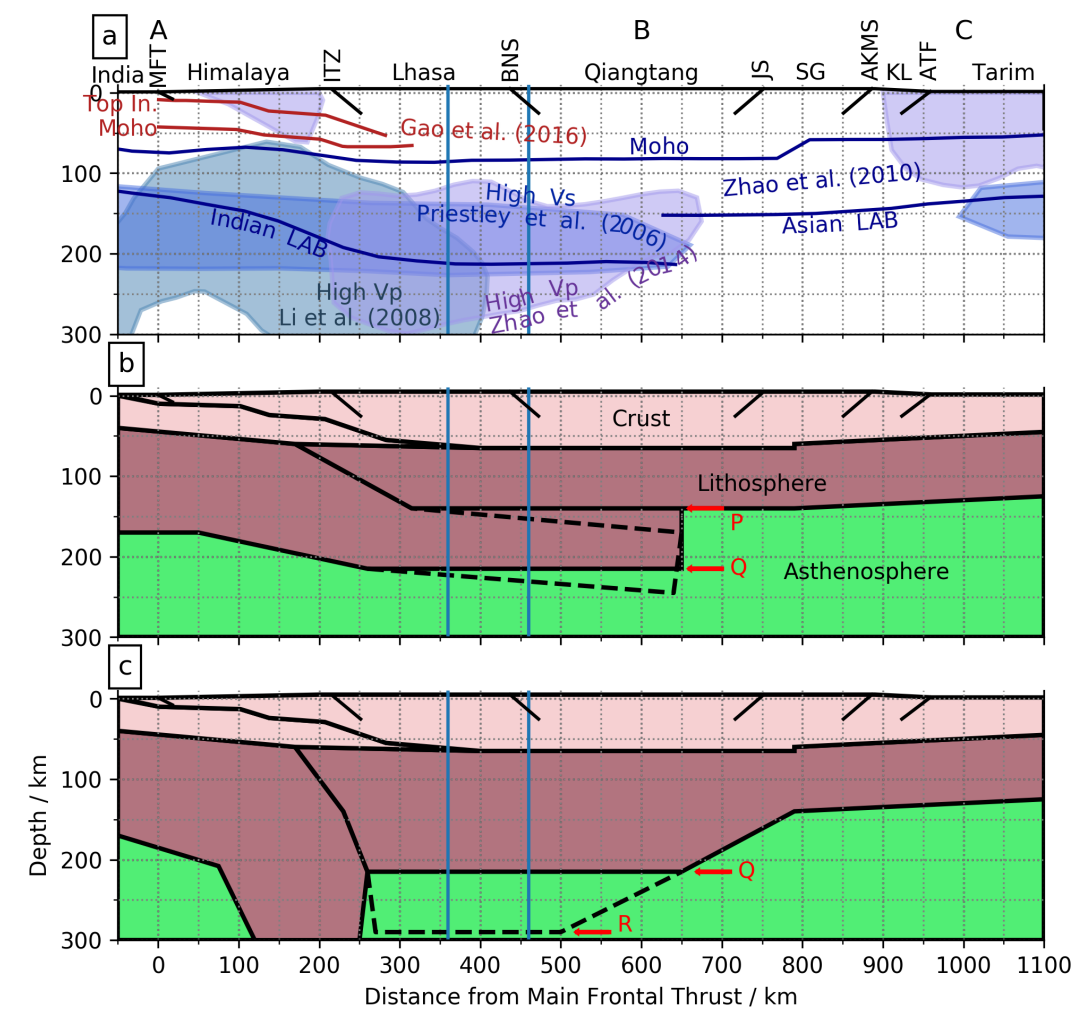

Figure 7: A compilation of published seismic cross-sections for western Tibet, followed by schematic tectonic cross-sections showing possible compensation depths. a) A compilation of published seismic cross-sections in southwestern Tibet. The free surface is shown at the top, and is labelled with terranes (horizontal) and lineaments (vertical). The line of the crosssection, including points $\mathrm{A}, \mathrm{B}$ and $\mathrm{C}$, is shown in figure 1 . The features shown are: the $2 \% V_{s v}$ contour from the surface wave tomography of Priestley et al. (2006, figure 8b), the $0.5 \% V_{p}$ contour from the $\mathrm{P}$-wave tomography of Li et al. (2008, figure $8 \mathrm{~b}$ ), the lithosphereasthenosphere boundary (LAB) and Moho from the S receiver functions of Zhao et al. 2010. figure $2 \mathrm{~b}$ ), the $1 \% V_{p}$ contour of Zhao et al. (2014), and the top of the Indian plate and the Moho from the study of Gao et al. 2016, figure 3a) which combined images from $\mathrm{P}$ receiver functions and active-source seismic profiles. The location of each cross-section is shown in map view in supplementary figure 7 The lateral offset of the different cross-sections is up to $400 \mathrm{~km}$. The cross-sections also have minor differences in bearing, which have been corrected by re-scaling. b) and c) Possible tectonic configurations, with corresponding compensation depths indicated by red arrows, with labels $\mathrm{P}, \mathrm{Q}$ and $\mathrm{R}$ corresponding to figure 6 and table 2 The region used for isostatic balance calculations is between the vertical blue lines (this is also the shaded region in figure 5 and the circled region in figure 8. In b), the Indian slab thrusts beneath Tibet. Two compensation depths are shown, depending on whether or not the lower slab is coupled to the upper shes. In c), the Eurasian plate thickens to form Tibet. Other abbreviations: Top In.: top of Indian plate, MFT: Main Frontal Thrust, ITZ: Indus-Tsangpo Suture, BNS: Bangong-Nujiang Suture, JS: Jinsha Suture, SG: Songpan-Ganze Terrane, AKMS: Anyimaqen-Kunlun-Muztagh Suture, KL: Kunlun Mountains, ATF: Altyn Tagh Fault. 


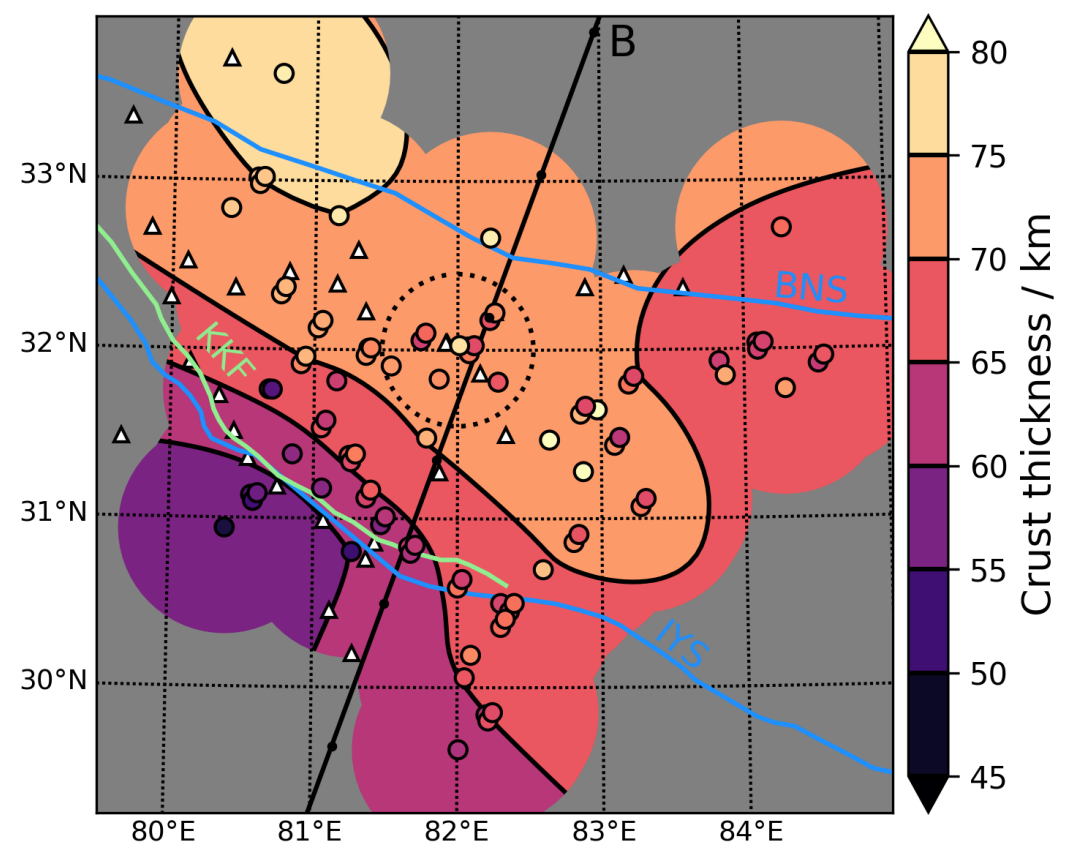

Figure 8: A map of crust thickness estimated using VDSS. Individual measurements are shown as coloured circles. These individual measurements are interpolated to give the coloured contours. The line of the cross-section A-B is shown in black, with the same $100 \mathrm{~km}$ markers as the map in figure 1. The black dotted circle encloses the measurements which were used to calculate the crust thickness of $70 \pm 4 \mathrm{~km}$ for isostasy calculations. Blue lines indicate the following suture zones: Indus-Yarlung (IYS) and Bangong-Nujiang (BNS). The Karakoram Fault (KKF) is shown as a pale green line. The stations of the network are shown as white triangles.

figure 8

The crust thickness measurements are also shown in the cross-section (figure 5). Even though the crust thickness measurements from VDSS are obtained independently of the shear wave speed structure, they are consistent: the base of the crust closely follows the $V_{s v}=4.05 \mathrm{~km} \mathrm{~s}^{-1}$ contour.

Our VDSS crust thickness measurements also provide an independent test of the estimates made by Gilligan et al. (2015), who fitted Rayleigh wave group speed dispersion and receiver functions. The two independent methods agree 
within the uncertainty bounds, as shown in supplementary figure 14. Given that the incoming $S s P m p$ pulse samples the mantle at large distance from the receiver (figure 3 a), in contrast to receiver function phases, the agreement between the two methods suggests that there are not significant lateral variations in the upper mantle along the ray paths. This may be partly because of the serendipitous source-receiver geometry (figure $3 \mathrm{~b}$ ), which results in ray paths which are approximately perpendicular to the convergence direction.

\subsection{Contributions to surface elevation}

We estimate that the isostatic elevation of the crust would be $7.4 \pm 1.5 \mathrm{~km}$ by first using 3 with the crust thickness estimate of $70 \pm 4 \mathrm{~km}$, and then subtracting of the reference height. Thus, the difference between this elevation and the true elevation, that is, the residual topography, is $-2.4 \pm 1.5 \mathrm{~km}$. Other parts of the study area have similar surface elevation, but different crust thickness, so the residual topography has lateral variations. In particular, in the northwest and east we find values of $-3.5 \mathrm{~km}$ and $-2.0 \mathrm{~km}$, respectively (supplementary figure 15.).

In order to estimate the contribution of the lithospheric mantle, we must subtract the dynamic topography. As discussed in section 1 the free-air anomaly of $30 \pm 20 \mathrm{mGal}$ suggests that the dynamic topography is positive and less than $0.6 \mathrm{~km}$. Taking the residual topography to be $-2.4 \pm 1.5 \mathrm{~km}$, this range of values of dynamic topography implies that lithospheric mantle is negatively buoyant and changes the surface elevation by -0.9 to $-4.5 \mathrm{~km}$. Contrary to our assertion that dynamic topography should be small and positive, five models of mantle flow presented by Flament et al. (2013, figure 4) indicate a downwelling dynamic topography, on average, of about $-0.5 \mathrm{~km}$ in this region. In this alternative case, we still find that the lithospheric mantle is negatively buoyant, but less so, with an elevation contribution in the range of -0.4 to $-3.4 \mathrm{~km}$.

\subsection{Density of the lithospheric mantle}

We can estimate the average density (relative to the reference mantle) of the lithospheric mantle from the isostatic balance (equation 2 or the geoid anomaly 


\begin{tabular}{lr|ccc}
\multirow{2}{*}{$\Delta \rho\left(\mathrm{kg} \mathrm{m}^{-3}\right)$} & \multicolumn{3}{|c}{ Lithosphere thickness $(\mathrm{km})$} \\
& & 75 & 150 & 225 \\
\hline \multirow{2}{*}{$\begin{array}{c}\text { Dynamic } \\
\text { topography }\end{array}$} & -0.5 & $100 \pm 70$ & $40 \pm 30$ & $20 \pm 20$ \\
$(\mathrm{~km})$ & 0.5 & $110 \pm 70$ & $50 \pm 30$ & $\mathbf{3 0} \pm \mathbf{2 0}$ \\
& $120 \pm 70$ & $50 \pm 30$ & $30 \pm 20$
\end{tabular}

Table 2: Average density excess $(\Delta \rho)$ of lithospheric mantle relative to reference mantle for various parameter combinations. The figure in bold is for the preferred model, as discussed in the text. The three choices of lithosphere thickness correspond to models $\mathrm{P}, \mathrm{Q}$ and $\mathrm{R}$ in figures 6 and 7

(equation (4). We do this for a range of plausible values of dynamic topography and lithosphere thickness, with the results shown in table 2, After taking into account the additional uncertainties which come from the other parameters, we can see that the density excess could be between 0 and $190 \mathrm{~kg} \mathrm{~m}^{-3}$. This is not a very tight constraint, but it shows that Tibet's lithospheric mantle is as dense or denser than the reference mantle, even when uncertainties are taken into account.

In our preferred model, the mantle lithosphere is thick $(225 \mathrm{~km})$ and the dynamic topography is negligible $(0 \mathrm{~km})$, as shown by the bold value in table 2 . These values yield an estimate of the mean density anomaly of the lithospheric mantle of $30 \pm 20 \mathrm{~kg} \mathrm{~m}^{-3}$ (around 1\%).

\section{Discussion}

\subsection{Geotherm and shear-wave-speed anomaly}

Our temperature estimate of $1330{ }^{\circ} \mathrm{C}$ at the base of the crust is consistent with estimates from melting experiments carried out on ultrapotassic volcanic rocks from the centre of the Qiangtang Terrane (Holbig and Grove, 2008, location shown as a red dot in inset of figure 1 as marked by the red dots in figure 6 . An and Shi (2007) also estimate mantle temperature from on a shear wave speed model from Rayleigh wave tomography and laboratory measurements of temperature sensitivity. Their estimates for the western Lhasa Terrane are shown in 
figure 6, including a stated $150{ }^{\circ} \mathrm{C}$ uncertainty. The disagreement below $150 \mathrm{~km}$ arises from differences in the tomographic models: they do not report high $V_{s}$ below about $200 \mathrm{~km}$, perhaps due to the shallower sensitivity of group speed with respect to phase speed.

The temperatures we observe are difficult to reconcile with with a model of a cold Indian slab thrusting beneath Tibet. Numerical modelling (Craig et al. 2012 figure $3 \mathrm{~b}$ ) suggests that advection is dominant over conduction (from the asthenosphere below and crust above), especially when close to the frontal thrust. Therefore, the main thermal effect would be a net downward translation of the geotherm by $30 \mathrm{~km}$ : underthrusting the Indian slab to the base of the Tibetan crust at around $50 \mathrm{~km}$ depth, and removing the top $20 \mathrm{~km}$ of India's crust. Considering a typical cratonic geotherm (e.g. figure 1 of Priestley et al. 2018 ), this would suggest a temperature anomaly of perhaps $800^{\circ} \mathrm{C}$ just beneath the Moho, and an average anomaly of around $400^{\circ} \mathrm{C}$, both of which are much lower than our temperature estimates.

Agius and Lebedev (2013) found a shear wave speed profile that would be compatible with the presence of such a cold Indian slab. They also inverted Rayleigh wave dispersion for shear wave speed in western Tibet, although they used a different method to estimate dispersion, based on interstation measurements, and they included Love waves. In the western Lhasa Terrane, they found a 90-km-thick layer with a high shear wave speed (almost $5 \mathrm{~km} \mathrm{~s}^{-1}$ ) in the uppermost mantle. Although we observe a similar Rayleigh wave dispersion curve, we prefer a model where the high wave speed anomalies are weaker but distributed down to greater depths in the mantle. This provides a better fit to the lowest-frequency part of our dataset, as well as avoiding strong peaks in the receiver functions, which are not observed. These comparisons are shown in supplementary figure 5 .

\subsection{Density of the lithospheric mantle}

In our preferred model, the average density excess of the lithospheric mantle is $30 \pm 20 \mathrm{~kg} \mathrm{~m}^{-3}$ relative to fertile, lherzolitic adiabatic mantle. The density 
excess could be due to both thermal and compositional effects. In section 3.2 we estimated that $20 \mathrm{~kg} \mathrm{~m}^{-3}$ of this excess density could be due to thermal contraction. In the case of a depleted, harzburgite composition, this thermal component $20 \mathrm{~kg} \mathrm{~m}^{-3}$ would combine with a compositional contrast of around $-60 \mathrm{~kg} \mathrm{~m}^{-3}$ (McKenzie and Priestley, 2016) for an excess density of $-40 \mathrm{~kg} \mathrm{~m}^{-3}$, which is incompatible with our results. Note that this conclusion still holds for our most extreme case, where the density excess is $20 \pm 20 \mathrm{~kg} \mathrm{~m}^{-3}$ (table 2 , upper right value).

Our preferred density excess of $30 \pm 20 \mathrm{~kg} \mathrm{~m}^{-3}$ can be explained (within error bars) by thermal contraction with no compositional anomaly relative to normal lherzolitic mantle; in section 3.2 , we estimated that thermal contraction would cause a density increase of $20 \mathrm{~kg} \mathrm{~m}^{-3}$. This could be consistent with a young lithospheric mantle formed by the compression of the former Andean-type Eurasian margin (figure 7 . $)$.

We cannot rule out the possibility of an even greater density anomaly (e.g. left column of table 2). Any density anomaly beyond the thermal component of around $20 \mathrm{~kg} \mathrm{~m}^{-3}$ should be due to compositional anomalies.

\subsection{Other studies of mantle lithosphere density and thickness}

Our study is not the first to conclude that the lithospheric mantle is denser than depleted harzburgite in western Tibet (or the adjacent regions). Vozar et al. (2014) used surface wave dispersion data (Agius and Lebedev, 2013) alongside magnetotelluric data to constrain petrological modelling. In the central Lhasa terrane, around $900 \mathrm{~km}$ east of our study region, they found the base of the lithosphere at a shallower depth of $180 \mathrm{~km}$. They also report that cratonic harzburgite compositions are too buoyant to match the observed topography, but argue that the required density can be matched by iron-rich harzburgites, such as those found in the Miocene Sailipu uppermost-mantle xenoliths near our study area. They observed low resistivities which required the presence of a small amount of water in the lithospheric mantle, consistent with the presence of phlogopite in the xenoliths. 
To the west of our study area, a similar study was carried out by Tunini et al. (2016). They used petrological modelling to fit elevation, Bouguer anomalies, geoid height, heat flow and seismic data, including refraction and reflection measurements, receiver functions, and P- and S-wave tomography. We can compare our results to the point about $700 \mathrm{~km}$ along their western cross-section, which is at a distance of around $500 \mathrm{~km}$ along strike (northwest) from the centre of our study area (supplementary figure 7). They estimate a lithospheric thickness of 280 to $300 \mathrm{~km}$, in agreement with our results. They also find that depleted lithospheric mantle compositions are too buoyant to fit the observed elevation (as well as P-wave velocities), and they prefer a fertile composition 'compatible with a generic lherzolitic mantle'.

More generally, Robert et al. (2017) produced a global model of crust and lithosphere thicknesses by fitting geoid anomalies and elevation, assuming local isostasy and a steady state geotherm. In our study region, they estimate the crust thickness to be 70 to $75 \mathrm{~km}$, and the base of the lithosphere to be at a depth of $270 \mathrm{~km}$ to $290 \mathrm{~km}$, in agreement with our results.

\subsection{Fate of Indian lithosphere}

If Indian lithosphere has underthrust this region of Tibet, the lithosphere mantle in this study region would consist of originally Indian lithosphere with much of the crust stripped away (figure $7 \mathrm{~b}$ ). Therefore, it might be expected to have a depleted, cratonic composition and corresponding cold geotherm, inconsistent with our results. One possible explanation is that the underthrust part of Indian slab does not have such a depleted composition. For example, the former northern margin of India could have been a younger orogenic belt or basin.

Another possibility is that Indian slab has undergone a chemical change after thrusting beneath Tibet. One candidate for compositional density excess is eclogite, which, in the mantle, is denser than peridotite by 5 to $10 \%$ Garber et al., 2018). Eclogite can form in the lower crust of mountain belts when water disturbs the metastability of granulite, a process hypothesised to take place in 
Tibet (Jackson et al., 2004). The gradual crust-mantle transition in Tibet could be a progressive increase in the fraction of eclogite with depth. Razi et al. (2014 also suggested that the upper mantle of western Tibet contains eclogite, on the basis of very high $\mathrm{P}$-wave speeds of up to $8.4 \mathrm{~km} \mathrm{~s}^{-1}$. However, it is not clear whether cratonic lithosphere could form eclogite during underthrusting.

Furthermore, rough calculations suggest that an unrealistic amount of eclogite would be required to counterbalance a depleted lithosphere. For example, if the lithospheric mantle is a mixture of depleted harzburgite and eclogite (compositional density anomalies of $-60 \mathrm{~kg} \mathrm{~m}^{-3}$ and e.g. $+200 \mathrm{~kg} \mathrm{~m}^{-3}$, respectively) with a thermal anomaly of $+20 \mathrm{~kg} \mathrm{~m}^{-3}$, then our preferred model (table 2 would require around $30 \%$ eclogite, which would cause much higher wave speeds than observed.

The composition before and after underthrusting are both uncertain, and both could act simultaneously to provide the observed negative buoyancy, while retaining the underthrusting model (figure $7 \mathrm{~b}$, solid line). Alternatively, it may be that the Indian slab is not part of the mantle lithosphere in this region of Tibet. This could be due to delamination of the underplated lithosphere (figure $7 \mathrm{~b}$, dashed line) or gravitational removal subsequent to underplating. The latter mechanism was proposed by Razi et al. (2016) on the basis of their body-wave tomography.

\section{Conclusions}

We find that the mantle lithosphere in western Tibet is, on average, denser than 'normal' mantle with a fertile, lherzolitic composition and an adiabatic geotherm. In our preferred model, a density anomaly of $30 \pm 20 \mathrm{~kg} \mathrm{~m}^{-3}$ is necessary to counterbalance the isostatic buoyancy of the crust, which we observe with VDSS to be $70 \pm 4 \mathrm{~km}$ thick. Additionally, we observe shear-wave speeds of $4.6 \mathrm{~km} \mathrm{~s}^{-1}$, on average, down to the base of the lithosphere at $290 \mathrm{~km}$, suggesting a geotherm which is $200{ }^{\circ} \mathrm{C}$ colder, on average, than the $1350{ }^{\circ} \mathrm{C}$ adiabat. Therefore, the density anomaly can be explained solely by thermal contraction, 
but we cannot rule out a compositional component, such as the formation of eclogite.

Neither the observed temperature nor density would be consistent with an underthrusting cratonic slab, which would be colder but less dense. We suggest that the now-subducted northern margin of India was not cratonic. However, alternative explanations are: 1) the underthrusting slab has undergone a compositional change to increase its density, 2) the slab is subducting and decoupled from the Tibetan lithosphere, or 3) the slab became gravitationally unstable and has detached and sunk into the mantle.

\section{Acknowledgements}

H. M.-D. thanks H. Fang, D. Forsyth, R. G. Green, A. Holt, V. Levin, C. $\mathrm{Yu}$ and especially L. Royden for helpful discussions, and to Schlumberger for a scholarship. He is also grateful to V. Levin and S. Roecker for making all seismograms from the Y2 network freely available through the IRIS Data Management

Centre. We also thank three anonymous reviewers for thorough, constructive reviews. Data were processed using ObsPy. All figures were prepared using Matplotlib, alongside the Cartopy library for mapping .

\section{Appendix}

The average density contrast between Tibet's mantle lithosphere and the reference adiabatic asthenosphere can be estimated from the geoid anomaly, $\Delta N$. For the model shown in figure 4 , the density contrast is given by

$$
\begin{aligned}
\rho_{t l m}-\rho_{d a}=-\left(\left(H_{t c}-\right.\right. & \left.\left.+H_{t l m}\right)^{2}-\left(H_{t c}-\epsilon\right)^{2}\right)^{-1} \times \\
\left(\frac{G \Delta N}{\pi g}-\rho_{t c} \epsilon^{2}\right. & \\
& +\left(\rho_{t c}-\rho_{r w}\right) H_{r w}^{2} \\
& +\left(\rho_{t c}-\rho_{r c}\right)\left(\left(H_{r w}+H_{r c}\right)^{2}-H_{r w}^{2}\right) \\
& \left.\left.+\left(\rho_{t c}-\rho_{s a}\right)\left(\left(H_{t c}-\epsilon\right)^{2}-\left(H_{r w}+H_{r c}\right)^{2}\right)\right)\right)
\end{aligned}
$$


$484 \quad 4987$.

where $G$ is the gravitational constant, $g$ is the standard acceleration due to gravity, and the other terms are given in table 1

\section{References}

Agius, M.R., Lebedev, S., 2013. Tibetan and indian lithospheres in the upper mantle beneath Tibet: Evidence from broadband surface-wave dispersion. Geochemistry, Geophysics, Geosystems 14, 4260-4281. URL: https://agupubs.onlinelibrary. wiley.com/doi/abs/10.1002/ggge.20274, doi 10.1002/ggge.20274, arXiv:https://agupubs.onlinelibrary.wiley.com/doi/pdf/10.1002/ggge.20274.

An, M., Shi, Y., 2007. Three-dimensional thermal structure of the Chinese continental crust and upper mantle. Science in China Series D: Earth Sciences 50, 1441-1451. URL: https://doi.org/10.1007/s11430-007-0071-3, doi 10. 1007/s11430-007-0071-3.

Artemieva, I.M., Billien, M., Lèvêque, J.J., Mooney, W.D., 2004. Shear wave velocity, seismic attenuation, and thermal structure of the continental upper mantle. Geophysical Journal International 157, 607628. URL: https://onlinelibrary.wiley.com/doi/abs/10.1111/ j.1365-246X.2004.02195.x doi 10.1111/j.1365-246X.2004.02195.x arXiv:https://onlinelibrary.wiley.com/doi/pdf/10.1111/j.1365-246X.2004.02195.x.

Barron, J., Priestley, K., 2009. Observations of frequency-dependent $\mathrm{S}_{n}$ propagation in northern Tibet. Geophysical Journal International 179,

475-488. URL: https://onlinelibrary.wiley.com/doi/abs/10.1111/ j.1365-246X.2009.04318.x doi 10.1111/j.1365-246X.2009.04318.x arXiv:https://onlinelibrary.wiley.com/doi/pdf/10.1111/j.1365-246X.2009.04318.x.

Bird, P., 1978. Initiation of intracontinental subduction in the Himalaya. Journal of Geophysical Research: Solid Earth 83, 4975-

4987. URL: https://agupubs.onlinelibrary.wiley.com/doi/ 
Bodin, T., Maupin, V., 2008. Resolution potential of surface wave phase velocity measurements at small arrays. Geophysical Journal International 172, 698-706. URL: http://dx.doi.org/10.1111/j.1365-246X.2007.03668.x. doi:10.1111/j.1365-246X.2007.03668.x

Brocher, T., 2005. Empirical relations between elastic wavespeed and density in the Earth's crust. Bulletin of the Seismological Society of America 95, 2081-2092. URL: https://doi.org/10.1785/0120050077, doi 10.1785/ 0120050077

Calò, M., Bodin, T., Romanowicz, B., 2016. Layered structure in the upper mantle across North America from joint inversion of long and short period seismic data. Earth and Planetary Science Letters 449,

164 - 175. URL: http://www.sciencedirect.com/science/article/pii/ S0012821X16302874, doi/https://doi.org/10.1016/j.epsl.2016.05.054

Carlson, R.L., Raskin, G.S., 1984. Density of the ocean crust. Nature 311, 555558. URL: https://doi.org/10.1038/311555a0, doi:10.1038/311555a0.

Christensen, N.I., 1996. Poisson's ratio and crustal seismology. Journal of Geophysical Research: Solid Earth 101, 3139-3156. URL: https://agupubs.onlinelibrary.wiley. com/doi/abs/10.1029/95JB03446, doi 10.1029/95JB03446, arXiv:https://agupubs.onlinelibrary.wiley.com/doi/pdf/10.1029/95JB03446.

Craig, T.J., Copley, A., Jackson, J., 2012. Thermal and tectonic consequences of India underthrusting Tibet. Earth and Planetary Science Letters 353-354, 231 - 239. URL: http://www.sciencedirect.com/science/article/pii/ S0012821X1200369X, doi https://doi.org/10.1016/j.epsl.2012.07.010

England, P., Houseman, G., 1989. Extension during continental convergence, with application to the Tibetan Plateau. 
Journal of Geophysical Research: Solid Earth 94, 17561-

17579. URL: https://agupubs.onlinelibrary.wiley.com/doi/ abs/10.1029/JB094iB12p17561, doi 10.1029/JB094iB12p17561, arXiv:https://agupubs.onlinelibrary.wiley.com/doi/pdf/10.1029/JB094iB12p17561

Flament, N., Gurnis, M., Müller, R.D., 2013. A review of observations and models of dynamic topography. Lithosphere 5, 189. URL: http://dx.doi. org/10.1130/L245.1, doi:10.1130/L245.1.

Forsyth, D.W., Li, A., 2005. Array Analysis of Two-Dimensional Variations in Surface Wave Phase Velocity and Azimuthal Anisotropy in the Presence of Multipathing Interference. American Geophysical Union (AGU). pp. 81-97. URL: https://agupubs.onlinelibrary. wiley.com/doi/abs/10.1029/157GM06, doi:10.1029/157GM06 arXiv:https://agupubs.onlinelibrary.wiley.com/doi/pdf/10.1029/157GM06.

Gale, A., Langmuir, C.H., Dalton, C.A., 2014. The global systematics of ocean ridge basalts and their origin. Journal of Petrology 55, 1051-1082. URL: http://dx.doi.org/10.1093/petrology/egu017, doi 10. 1093/petrology/egu017.

Gan, W., Zhang, P., Shen, Z.K., Niu, Z., Wang, M., Wan, Y., Zhou, D., Cheng, J., 2007. Present-day crustal motion within the Tibetan Plateau inferred from GPS measurements. Journal of Geophysical Research: Solid Earth 112. URL: https://agupubs.onlinelibrary. wiley.com/doi/abs/10.1029/2005JB004120, doi:10.1029/2005JB004120 arXiv:https://agupubs.onlinelibrary.wiley.com/doi/pdf/10.1029/2005JB004120.

Gao, R., Lu, Z., Klemperer, S.L., Wang, H., Dong, S., Li, W., Li, H., 2016. Crustal-scale duplexing beneath the Yarlung-Zangbo suture in the western Himalaya. Nature Geoscience 9, 555-561. URL: https://doi.org/10.1038/ ngeo2730 article.

Garber, J.M., Maurya, S., Hernandez, J.A., Duncan, M.S., Zeng, L., Zhang, H.L., Faul, U., McCammon, C., Montagner, J.P., Moresi, 
L., Romanowicz, B.A., Rudnick, R.L., Stixrude, L., 2018. Multidisciplinary constraints on the abundance of diamond and eclogite in the cratonic lithosphere. Geochemistry, Geophysics, Geosystems 19, 2062-2086. URL: https://agupubs.onlinelibrary.wiley. com/doi/abs/10.1029/2018GC007534, doi 10.1029/2018GC007534, arXiv:https://agupubs.onlinelibrary.wiley.com/doi/pdf/10.1029/2018GC007534

Gilligan, A., Priestley, K.F., Roecker, S.W., Levin, V., Rai, S.S., 2015. The crustal structure of the western Himalayas and Tibet. Journal of Geophysical Research: Solid Earth 120, 3946-3964. URL: http://dx.doi.org/10.1002/ 2015JB011891, doi:10.1002/2015JB011891. 2015JB011891.

Herrmann, R.B., 2013. Computer Programs in Seismology: An evolving tool for instruction and research. Seismological Research Letters 84, 1081. URL: http://dx.doi.org/10.1785/0220110096 doi:10.1785/0220110096

Holbig, E.S., Grove, T.L., 2008. Mantle melting beneath the Tibetan Plateau: Experimental constraints on ultrapotassic magmatism. Journal of Geophysical Research: Solid Earth 113. URL: https://agupubs.onlinelibrary. wiley.com/doi/abs/10.1029/2007JB005149, doi:10.1029/2007JB005149, arXiv:https://agupubs.onlinelibrary.wiley.com/doi/pdf/10.1029/2007JB005149

Jackson, J., Austrheim, H., McKenzie, D., Priestley, K., 2004. Metastability, mechanical strength, and the support of mountain belts. Geology 32, 625 . URL: http://dx.doi.org/10.1130/G20397.1, doi/10.1130/G20397.1.

Kennett, B.L.N., 1974. On variational principles and matrix methods in elastodynamics. Geophysical Journal of the Royal Astronomical Society 37, 391405. URL: http://dx.doi.org/10.1111/j.1365-246X.1974.tb04092.x, doi:10.1111/j.1365-246X.1974.tb04092.x.

Li, C., van der Hilst, R.D., Meltzer, A.S., Engdahl, E.R., $2008 . \quad$ Subduction of the Indian lithosphere beneath the Tibetan Plateau and Burma. Earth and Planetary Science Letters 274, 157-168. URL: http: 
//www.sciencedirect.com/science/article/pii/S0012821X08004500, doi:https://doi.org/10.1016/j.epsl.2008.07.016.

Liu, T., Klemperer, S.L., Yu, C., Ning, J., 2018. Post-critical SsPmp and its applications to Virtual Deep Seismic Sounding (VDSS) 1: Sensitivity to lithospheric 1-D and 2-D structure. Geophysical Journal International 215, 880-894. URL: https://dx.doi.org/10.1093/gji/ggy307, doi 10.1093/gji/ggy307 arXiv:http://oup.prod.sis.lan/gji/article-pdf/215/2/880/25536519/ggy307.pdf

McKenzie, D., Priestley, K., 2016. Speculations on the formation of cratons and cratonic basins. Earth and Planetary Science Letters 435, 94 - 104. URL: http://www.sciencedirect.com/science/article/pii/ S0012821X15007736 doi/https://doi.org/10.1016/j.epsl.2015.12.010

Molnar, P., Boos, W.R., Battisti, D.S., 2010. Orographic controls on climate and paleoclimate of Asia: Thermal and mechanical roles for the Tibetan Plateau. Annual Review of Earth and Planetary Sciences 38, 77-102. URL: https://doi.org/10.1146/annurev-earth-040809-152456 doi10.1146/ annurev-earth-040809-152456, arXiv:https://doi.org/10.1146/annurev-earth-040809-152456.

Molnar, P., England, P., Martinod, J., 1993. Mantle dynamics, uplift of the Tibetan Plateau, and the Indian Monsoon. Reviews of Geophysics 31, 357-396. URL: https://agupubs.onlinelibrary. wiley.com/doi/abs/10.1029/93RG02030 doi 10.1029/93RG02030 arXiv:https://agupubs.onlinelibrary.wiley.com/doi/pdf/10.1029/93RG02030.

Molnar, P., England, P.C., Jones, C.H., 2015. Mantle dynamics, isostasy, and the support of high terrain. Journal of Geophysical Research: Solid Earth 120, 1932-1957. URL: https://agupubs.onlinelibrary. wiley.com/doi/abs/10.1002/2014JB011724, doi:10.1002/2014JB011724, arXiv:https://agupubs.onlinelibrary.wiley.com/doi/pdf/10.1002/2014JB011724.

Murodov, D., Zhao, J., Xu, Q., Liu, H., Pei, S., 2018. Complex N-S variations in Moho depth and $V_{p} / V_{s}$ ratio beneath the western Tibetan Plateau as revealed 
by receiver function analysis. Geophysical Journal International 214, 895-906. URL: http://dx.doi.org/10.1093/gji/ggy170, doi 10.1093/gji/ggy170

Pavlis, N.K., Holmes, S.A., Kenyon, S.C., Factor, J.K., 2012. The development and evaluation of the Earth Gravitational Model 2008 (EGM2008). Journal of Geophysical Research: Solid Earth 117. URL: https://agupubs.onlinelibrary.wiley. com/doi/abs/10.1029/2011JB008916, doi:10.1029/2011JB008916, arXiv:https://agupubs.onlinelibrary.wiley.com/doi/pdf/10.1029/2011JB008916

Priestley, K., Debayle, E., McKenzie, D., Pilidou, S., 2006. Upper mantle structure of eastern Asia from multimode surface waveform tomography. Journal of Geophysical Research: Solid Earth 111. URL: http://dx.doi.org/10. 1029/2005JB004082, doi 10.1029/2005JB004082, b10304.

Priestley, K., McKenzie, D., 2006. The thermal structure of the lithosphere from shear wave velocities. Earth and Planetary Science Letters 244, 285 - 301. URL: http://www.sciencedirect.com/science/article/pii/ S0012821X06000331, doi/https://doi.org/10.1016/j.epsl.2006.01.008

Priestley, K., McKenzie, D., 2013. The relationship between shear wave velocity, temperature, attenuation and viscosity in the shallow part of the mantle. Earth and Planetary Science Letters 381, 78

- 91. URL: http://www.sciencedirect.com/science/article/pii/ S0012821X13004482, doi/https://doi.org/10.1016/j.epsl.2013.08.022

Priestley, K., McKenzie, D., Ho, T., 2018. A Lithosphere-Asthenosphere Boundary - a Global Model Derived from Multimode Surface-Wave Tomography and Petrology. American Geophysical Union (AGU). chapter 6.

pp. 111-123. URL: https://agupubs.onlinelibrary.wiley.com/doi/ abs/10.1002/9781119249740.ch6 doi 10.1002/9781119249740.ch6, arXiv:https://agupubs.onlinelibrary.wiley.com/doi/pdf/10.1002/9781119249740.ch6.

Randall, G.E., 1994. Efficient calculation of complete differential seismograms for laterally homogeneous Earth models. Geophysical Journal Inter- 
national 118, 245-254. URL: http://dx.doi.org/10.1111/j.1365-246X. 1994.tb04687.x doi 10.1111/j.1365-246X.1994.tb04687.x

Razi, A.S., Levin, V., Roecker, S.W., Huang, G.c.D., 2014. Crustal and uppermost mantle structure beneath western Tibet using seismic traveltime tomography. Geochemistry, Geophysics, Geosystems 15, 434-452. URL: http://dx.doi.org/10.1002/2013GC005143, doi:10.1002/2013GC005143.

Razi, A.S., Roecker, S.W., Levin, V., 2016. The fate of the Indian lithosphere beneath western Tibet: Upper mantle elastic wave speed structure from a joint teleseismic and regional body wave tomographic study. Physics of the Earth and Planetary Interiors 251, 11 - 23. URL: http://www.sciencedirect.com/science/article/pii/ S0031920115001685, doi/https://doi.org/10.1016/j.pepi.2015.12.001

Robert, A.M.M., Fernàndez, M., Jiménez-Munt, I., Vergés, J., 2017. Lithospheric structure in Central Eurasia derived from elevation, geoid anomaly and thermal analysis. Geological Society, London, Special Publications 427, 271-293. URL: https: //sp.lyellcollection.org/content/427/1/271, doi:10.1144/SP427.10, arXiv:https://sp.lyellcollection.org/content/427/1/271.full.pdf.

Stixrude, L., Lithgow-Bertelloni, C., 2007. Influence of phase transformations on lateral heterogeneity and dynamics in Earth's mantle. Earth and Planetary Science Letters 263, 45 - 55. URL: http: //www.sciencedirect.com/science/article/pii/S0012821X07005377, doi:https://doi.org/10.1016/j.epsl.2007.08.027

Styron, R., Taylor, M., Okoronkwo, K., 2010. Database of active structures from the Indo-Asian collision. Eos, Transactions American Geophysical Union 91, 181-182. URL: https://agupubs . onlinelibrary.wiley.com/doi/abs/10. 1029/2010E0200001, doi 10.1029/2010E0200001.

Tseng, T.L., Chen, W.P., Nowack, R.L., 2009. Northward thinning of 
Tibetan crust revealed by virtual seismic profiles. Geophysical Research Letters 36. URL: https://agupubs.onlinelibrary.wiley. com/doi/abs/10.1029/2009GL040457, doi:10.1029/2009GL040457 arXiv:https://agupubs.onlinelibrary.wiley.com/doi/pdf/10.1029/2009GL040457

Tunini, L., Jiménez-Munt, I., Fernandez, M., Vergés, J., Villaseñor, A., Melchiorre, M., Afonso, J.C., 2016. Geophysical-petrological model of the crust and upper mantle in the India-Eurasia collision zone.

Tectonics 35, 1642-1669. URL: https://agupubs.onlinelibrary. wiley.com/doi/abs/10.1002/2016TC004161, doi:10.1002/2016TC004161, arXiv:https://agupubs.onlinelibrary.wiley.com/doi/pdf/10.1002/2016TC004161.

Turcotte, D., Schubert, G., 2014. Geodynamics. 3rd ed., Cambridge University Press.

Vozar, J., Jones, A.G., Fullea, J., Agius, M.R., Lebedev, S., Le Pape, F., Wei, W., 2014. Integrated geophysical-petrological modeling of lithosphere-asthenosphere boundary in central Tibet using electromagnetic and seismic data. Geochemistry, Geophysics, Geosystems 15, 3965-3988. URL: https://agupubs.onlinelibrary.wiley. com/doi/abs/10.1002/2014GC005365, doi 10.1002/2014GC005365 arXiv:https://agupubs.onlinelibrary.wiley.com/doi/pdf/10.1002/2014GC005365

White, R.S., McKenzie, D., O'Nions, R.K., 1992. Oceanic crustal thickness from seismic measurements and rare earth element inversions. Journal of Geophysical Research: Solid Earth 97, 1968319715. URL: https://agupubs.onlinelibrary.wiley.com/doi/abs/10. 1029/92JB01749, doi $10.1029 / 92 J B 01749$.

Yang, Y., Forsyth, D.W., 2006a. Rayleigh wave phase velocities, small-scale convection, and azimuthal anisotropy beneath southern California. Journal of Geophysical Research: Solid
Earth 111.
URL: https://agupubs.onlinelibrary.wiley. 
Yang, Y., Forsyth, D.W., 2006b. Regional tomographic inversion of the amplitude and phase of Rayleigh waves with 2-D sensitivity kernels. Geophysical Journal International 166, 1148-1160. URL: $\quad$ https://onlinelibrary.wiley.com/doi/abs/10.1111/j. 1365-246X.2006.02972.x doi $10.1111 / \mathrm{j} .1365-246 \mathrm{X} .2006 .02972 . \mathrm{x}$, arXiv:https://onlinelibrary.wiley.com/doi/pdf/10.1111/j.1365-246X.2006.02972.x.

Yu, C., Chen, W.P., van der Hilst, R.D., 2016. Constraints on residual topography and crustal properties in the western United States from virtual deep seismic sounding. Journal of Geophysical Research: Solid Earth 121, 5917-5930. URL: http://dx.doi.org/10.1002/2016JB013046, doi 10. 1002/2016JB013046. 2016JB013046.

Yu, C.Q., Chen, W.P., Ning, J.Y., Tao, K., Tseng, T.L., Fang, X.D., Chen, Y.J., van der Hilst, R.D., 2012. Thick crust beneath the Ordos plateau: Implications for instability of the North China craton. Earth and Planetary Science Letters 357-358, 3661 375. URL: http://www.sciencedirect.com/science/article/pii/ S0012821X12005237, doi/https://doi.org/10.1016/j.epsl.2012.09.027

Zhao, J., Yuan, X., Liu, H., Kumar, P., Pei, S., Kind, R., Zhang, Z., Teng, J., Ding, L., Gao, X., Xu, Q., Wang, W., 2010. The boundary between the Indian and Asian tectonic plates below Tibet. Proceedings of the National Academy of Sciences 107, 11229-11233. URL: https: //www.pnas.org/content/107/25/11229, doi 10.1073/pnas.1001921107 arXiv:https://www.pnas.org/content/107/25/11229.full.pdf.

Zhao, J., Zhao, D., Zhang, H., Liu, H., Huang, Y., Cheng, H., Wang, W., 2014. P-wave tomography and dynamics of the crust and upper mantle beneath western Tibet. Gondwana Research 25, 1690 
712

713

714

715

716

717

718

- 1699. URL: http://wWw.sciencedirect.com/science/article/pii/ S1342937X13002256, doi https://doi.org/10.1016/j.gr.2013.06.020.

Zhu, L., Kanamori, H., 2000. Moho depth variation in southern California from teleseismic receiver functions. Journal of Geophysical Research:

n Solid Earth 105, 2969-2980. URL: https://agupubs.onlinelibrary. wiley.com/doi/abs/10.1029/1999JB900322, doi:10.1029/1999JB900322, arXiv:https://agupubs.onlinelibrary.wiley.com/doi/pdf/10.1029/1999JB900322. 


\begin{tabular}{llcccc} 
Region & UTC origin time & Lon. $\left({ }^{\circ} \mathbf{E}\right)$ & Lat. $\left({ }^{\circ} \mathbf{N}\right)$ & Depth $(\mathbf{k m})$ & Mag. $\left(M_{w}\right)$ \\
\hline Helmahera Island & 2008-09-11 00:00:02.70 & 127.36 & 1.88 & 96 & 6.6 \\
South of Honshu & 2009-08-09 10:55:55.11 & 137.94 & 33.17 & 292 & 7.1 \\
Celebes Sea & 2009-10-07 21:41:13.27 & 122.37 & 4.08 & 574 & 6.8 \\
Mindanao & $2010-07-2323: 15: 10.19$ & 123.26 & 6.78 & 641 & 7.5 \\
Mindanao & 2010-07-29 07:31:56.24 & 123.22 & 6.55 & 618 & 6.6 \\
Bali Sea & $2011-03-1017: 08: 36.86$ & 116.72 & -6.87 & 511 & 6.5
\end{tabular}

Supplementary Table 1: Earthquake sources used for virtual deep seismic sounding. 
$\mathrm{T}=20 \mathrm{~s}$

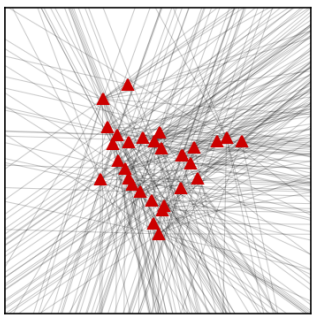

$\mathrm{T}=40 \mathrm{~s}$

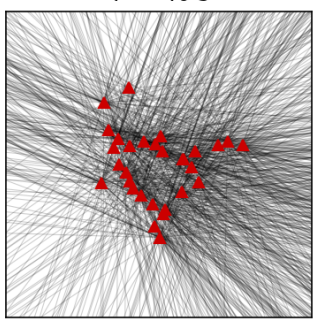

$T=60 \mathrm{~s}$

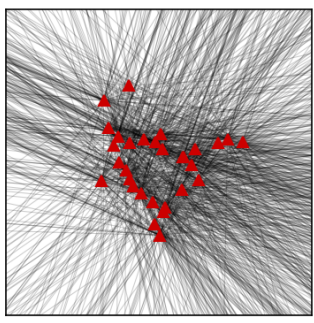

$\mathrm{T}=120 \mathrm{~s}$

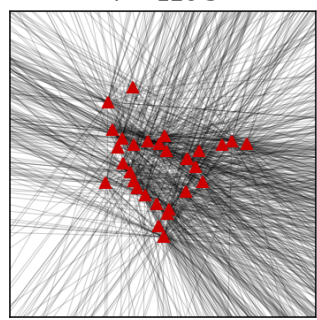

$\mathrm{T}=25 \mathrm{~s}$

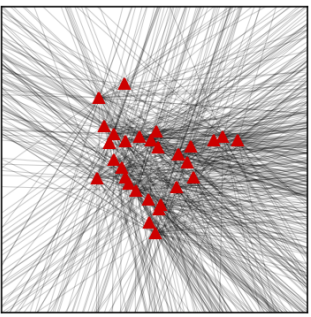

$\mathrm{T}=44 \mathrm{~s}$

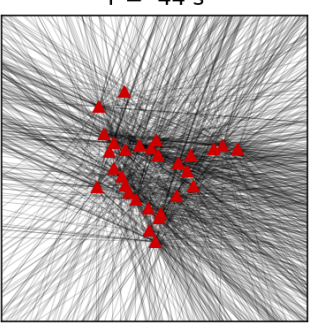

$\mathrm{T}=80 \mathrm{~s}$

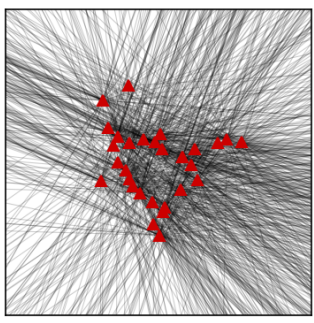

$\mathrm{T}=143 \mathrm{~s}$

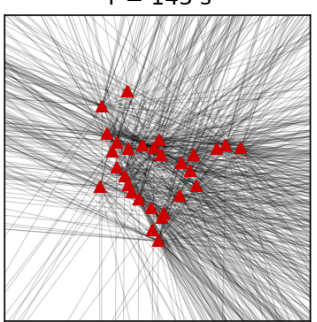

$\mathrm{T}=30 \mathrm{~s}$

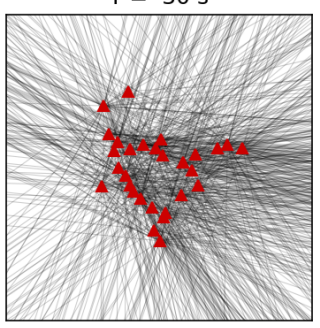

$\mathrm{T}=50 \mathrm{~s}$

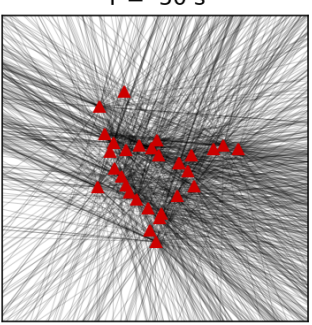

$\mathrm{T}=100 \mathrm{~s}$

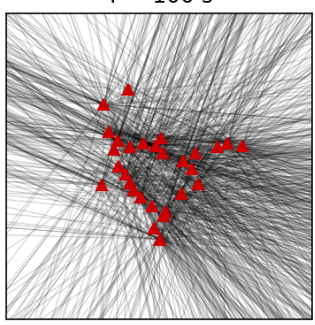

Supplementary Figure 1: Ray path diagrams for each frequency band used in the two-planewave inversion. Each panel is labelled with the central frequency of the band. Each grey line is a great-circle path which connects one event with one station where that event was observed with a high signal-to-noise ratio. The projection is azimuthal equidistant, centred on the network. 

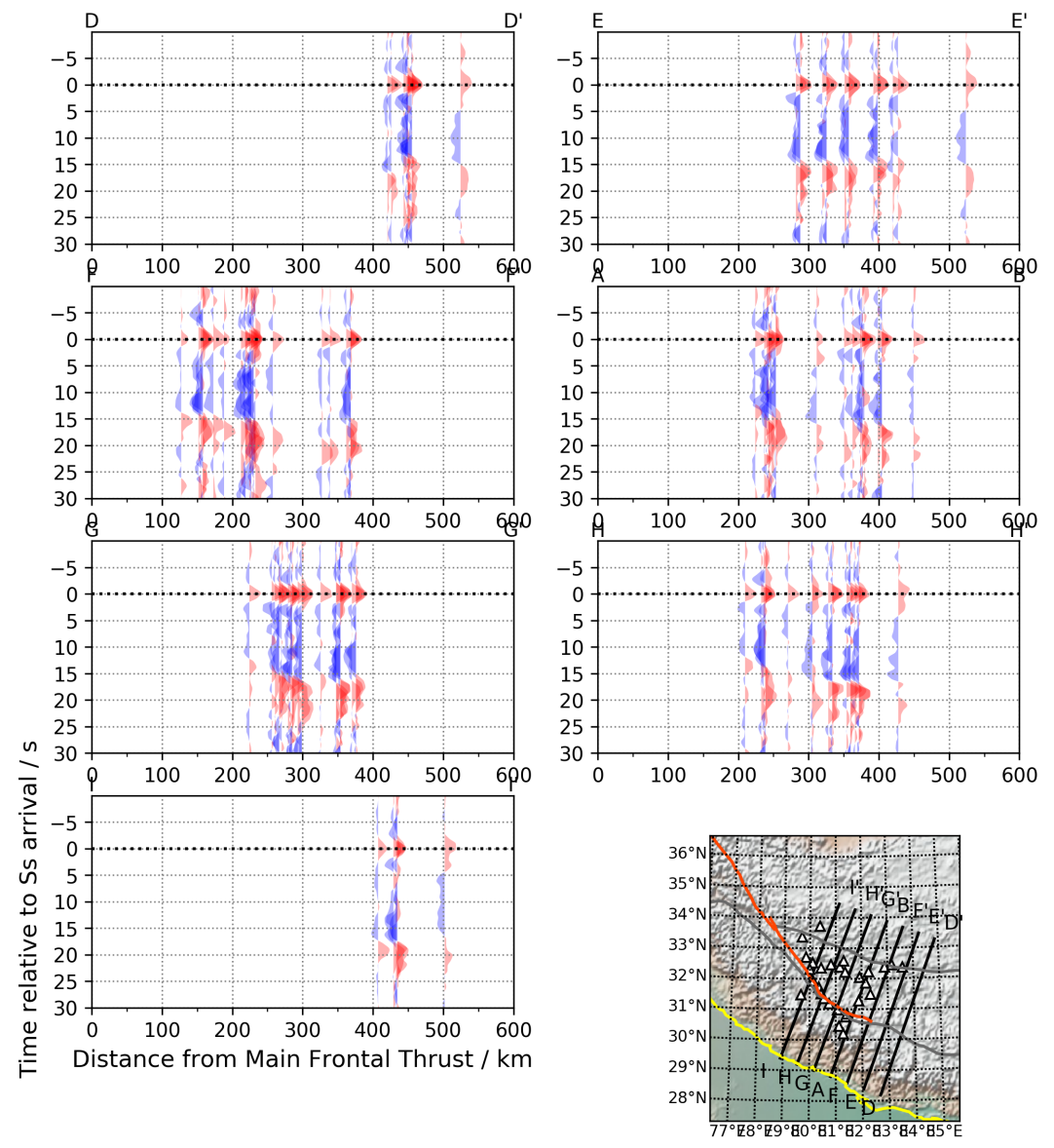

Supplementary Figure 2: Additional VDSS seismic sections. The location of each cross-section is shown in the lower right panel. Note that section A-B is the same as in figure 5 and the naming of the sections is the same as in supplementary figure 6 See the caption for figure $3 \mathrm{~d}$ for a description of the seismic sections. In these sections, seismograms are only shown for stations where the Moho reflection point was within $35 \mathrm{~km}$ of the cross-section, instead of the $100 \mathrm{~km}$ threshold used in figure 3 The map panel also has lines showing the Main Frontal Thrust (yellow), the Karakoram Fault (orange), and the Indus-Yarlung and Bangong-Nujiang sutures (grey lines). 


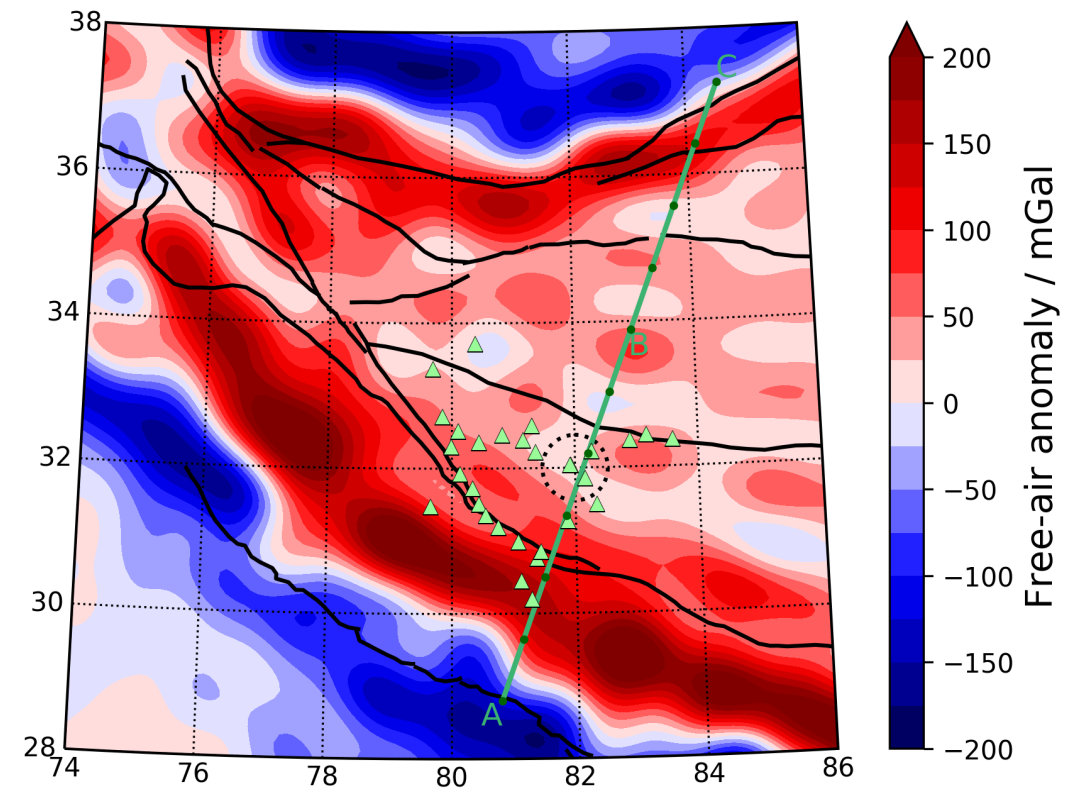

Supplementary Figure 3: Free-air gravity anomalies in western Tibet and the surrounding area from the EGM2008 model (Pavlis et al. 2012). The model is expanded to angular order 300 , corresponding to a wavelength of around $130 \mathrm{~km}$. The map projection, lineaments, cross-section from A to $\mathrm{C}$, and seismometers are all the same as in figure 1 


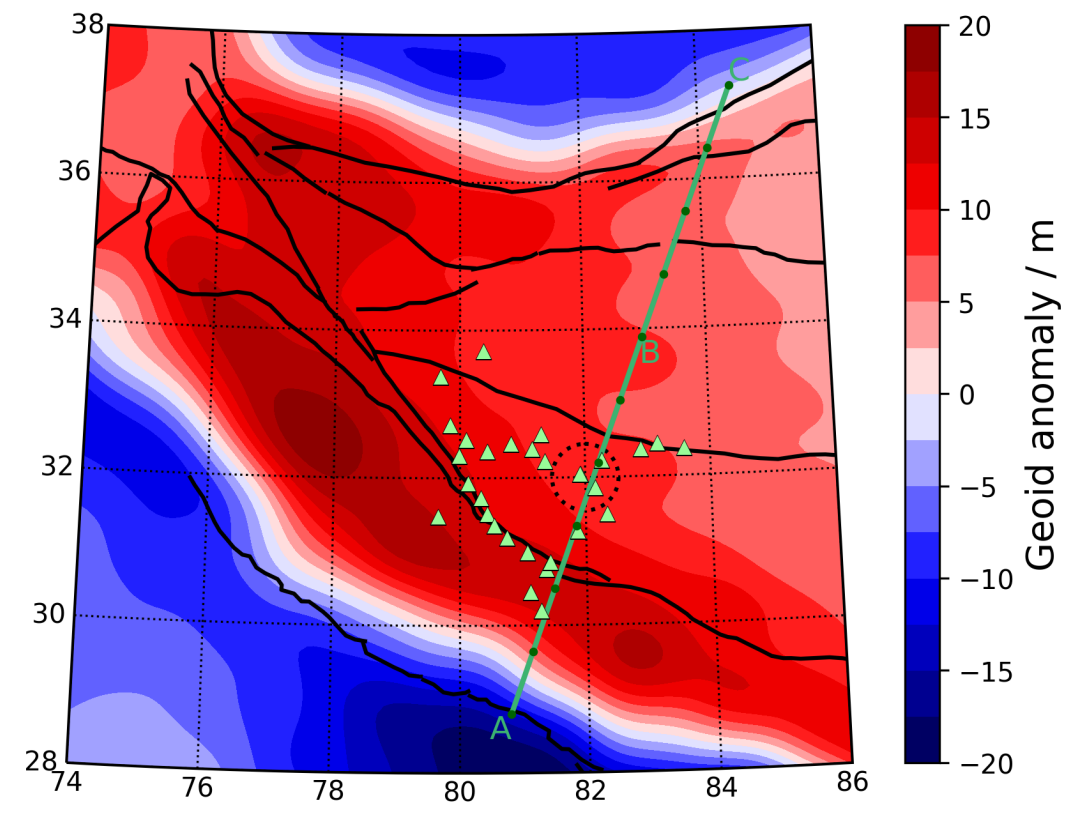

Supplementary Figure 4: Geoid anomalies in western Tibet and the surrounding area from the EGM2008 model (Pavlis et al., 2012). The model is expanded between angular orders of 20 and 300 , corresponding to a range of wavelengths from around $130 \mathrm{~km}$ to around $2000 \mathrm{~km}$. The map projection, lineaments, cross-section from A to C, and seismometers are all the same as in figure 1. 

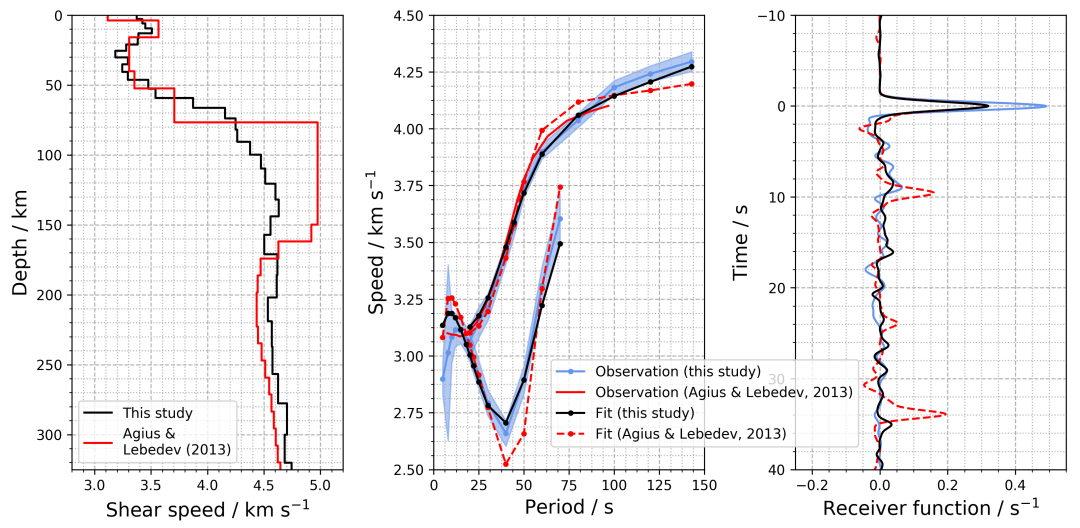

Supplementary Figure 5: An example of the shear wave speed inversion for station WT01. The left panel shows the final shear wave speed model. The middle panel shows the phase speed dispersion curve (upper line) observed at this location in the two-plane-wave inversion and the group speed dispersion curve (lower line) from Gilligan et al. (2015). The right panel shows the stacked receiver function for this station from Gilligan et al. (2015). Also shown are the fits to the observations calculated from the shear wave speed model, and a comparison with the observations and model of Agius and Lebedev (2013). 


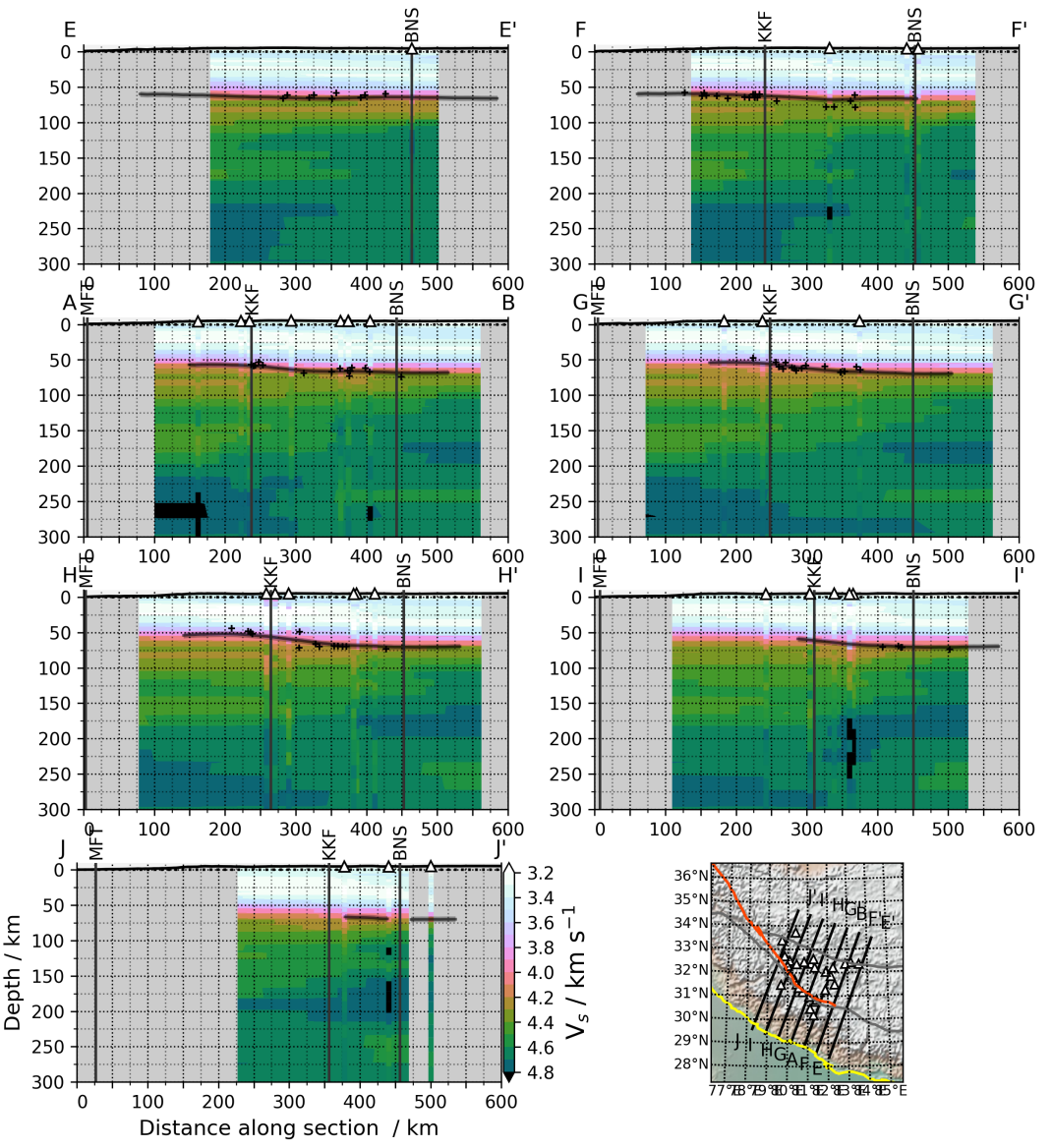

Supplementary Figure 6: Additional cross-sections through the models of shear wave speed and crust thickness. The location of each cross-section is shown in the lower right panel. Note that section $\mathrm{A}-\mathrm{B}$ is the same as in figure 5 and the naming of the sections is the same as in supplementary figure 2 See the caption for the main panel of figure 5 for a description of the cross-sections. Note the following differences: i) no vertical exaggeration is used for the topography; ii) the predicted isostatic elevation is not shown; iii) vertical sections beneath each station are shown here as coloured ribbons. The map panel also has lines showing the Main Frontal Thrust (yellow), the Karakoram Fault (orange), and the Indus-Yarlung and Bangong-Nujiang sutures (grey lines). 


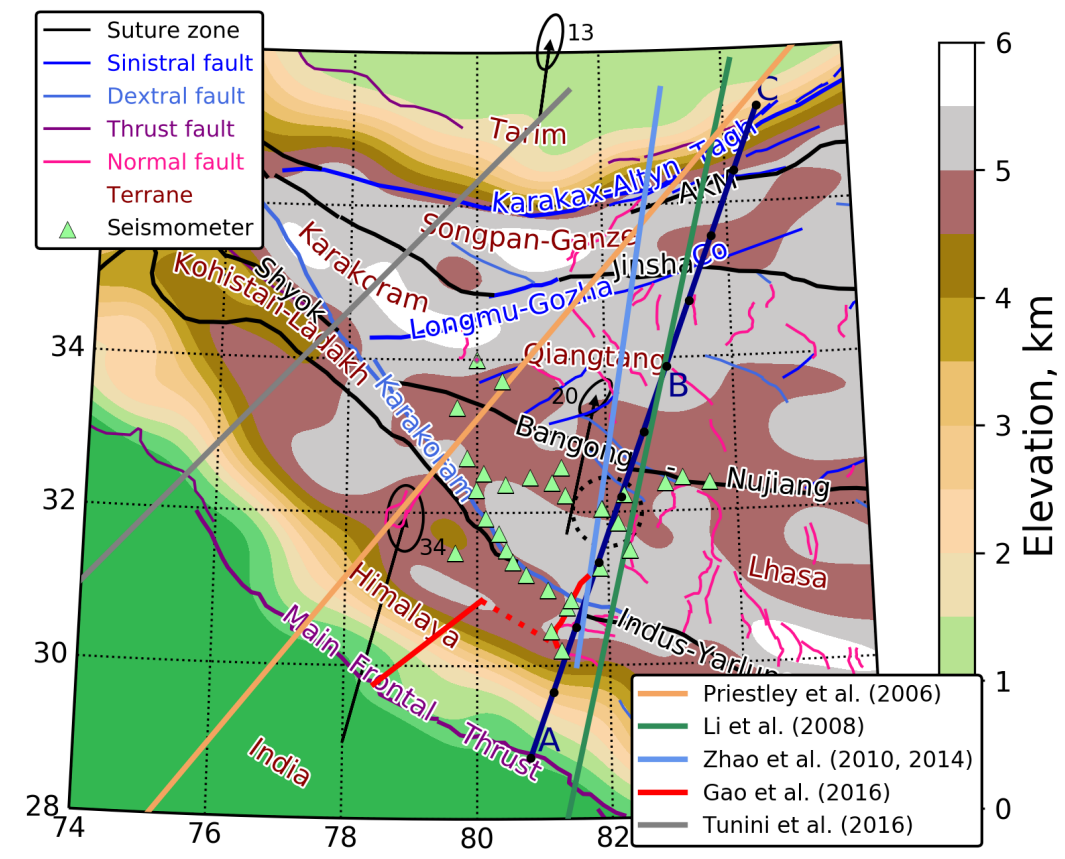

Supplementary Figure 7: A map showing the location of the four seismic cross-sections by previous workers, as shown in figure 7 The map is otherwise the same as figure 1 


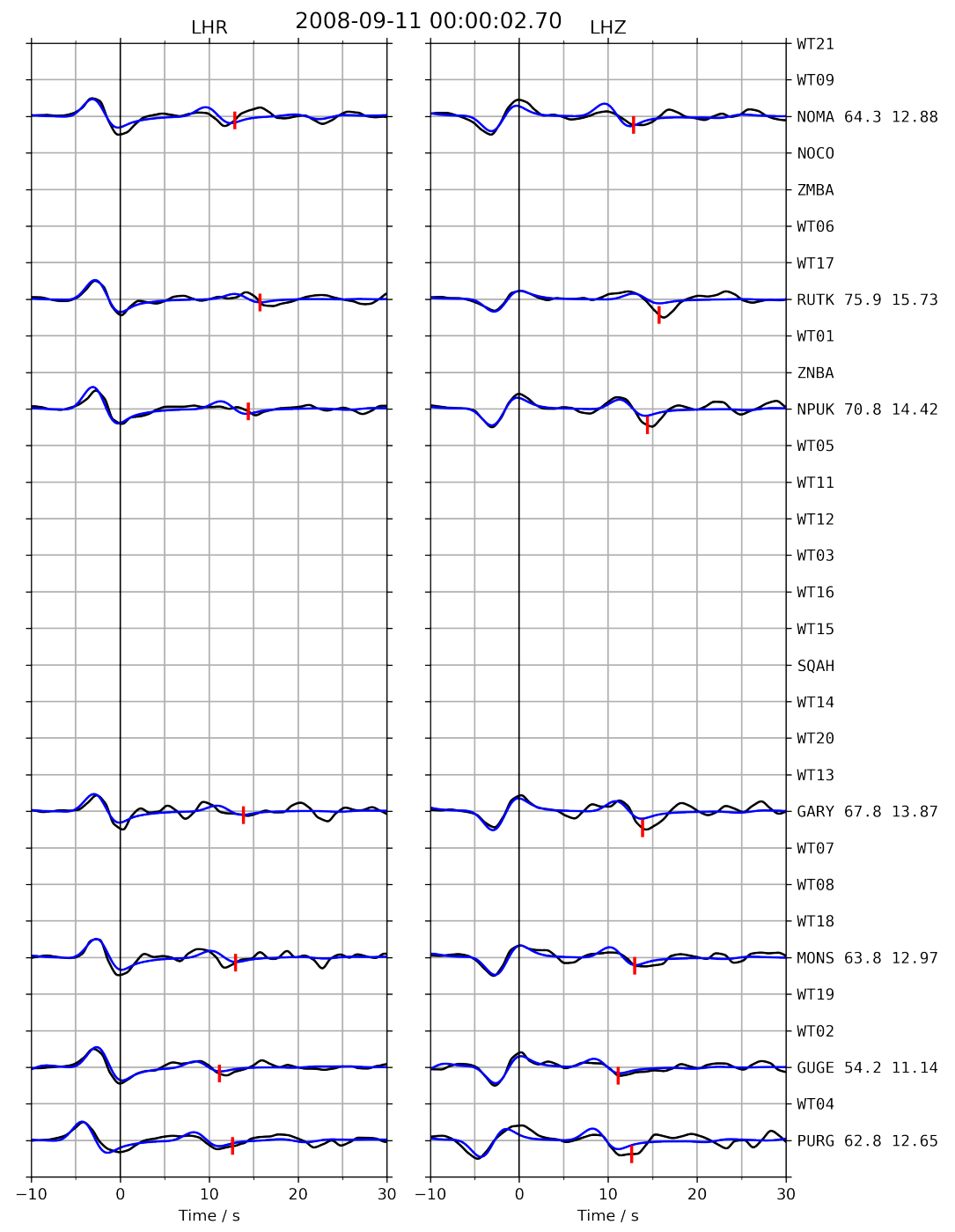

Supplementary Figure 8: Comparison of data (black lines) and fit (blue lines) for the earthquake event specified at the top. The vertical and radial components are shown on the rightand left-hand sides, respectively. The labels on the right-hand edge include the station code, estimated crust thickness (in $\mathrm{km}$ ) and corresponding value of $T_{S s P m p-S s}$ (in s), which is also marked by a red bar on the seismogram. Stations are ordered by increasing distance from the Main Frontal Thrust from bottom to top. 


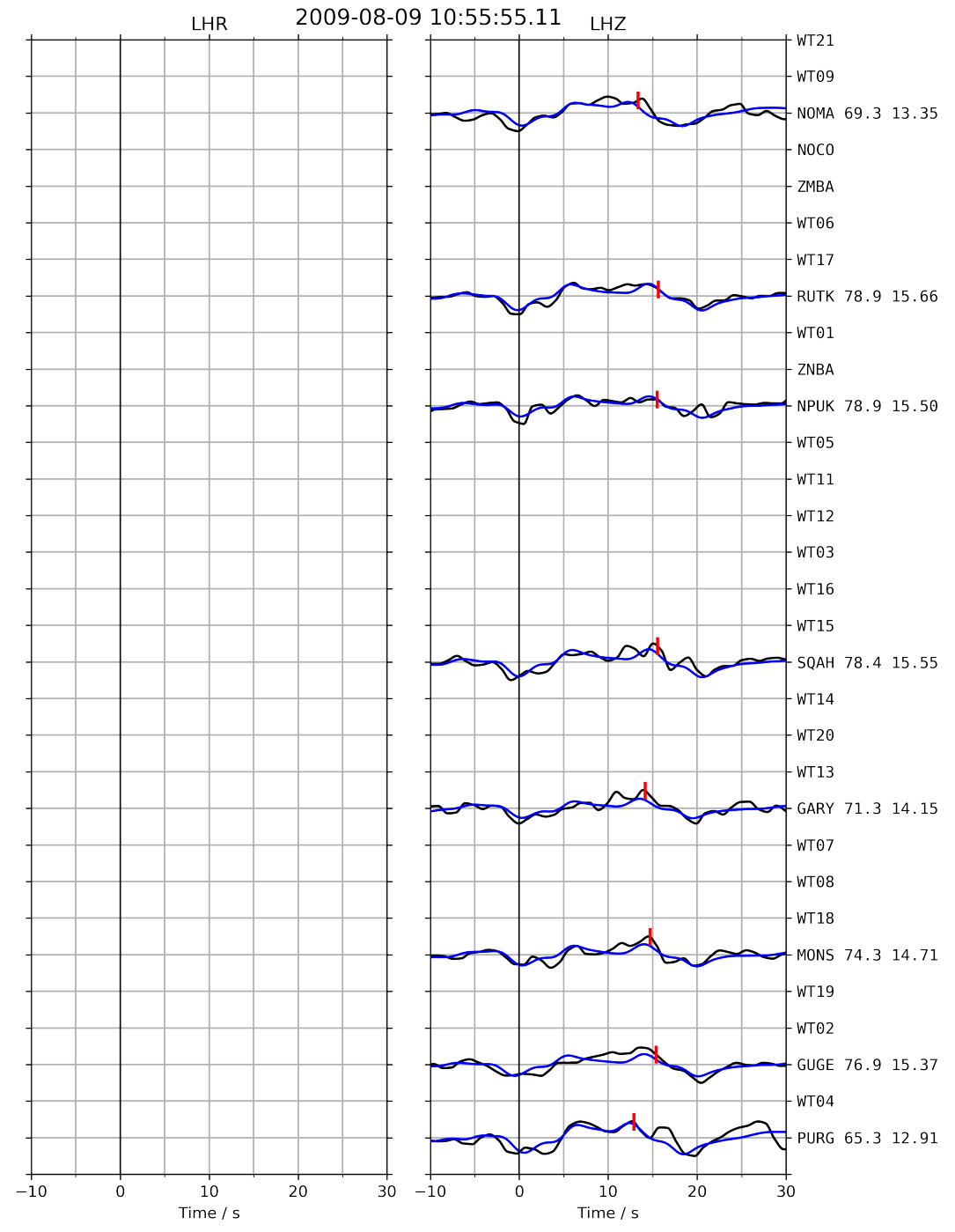

Supplementary Figure 9: See caption for supplementary figure 8 


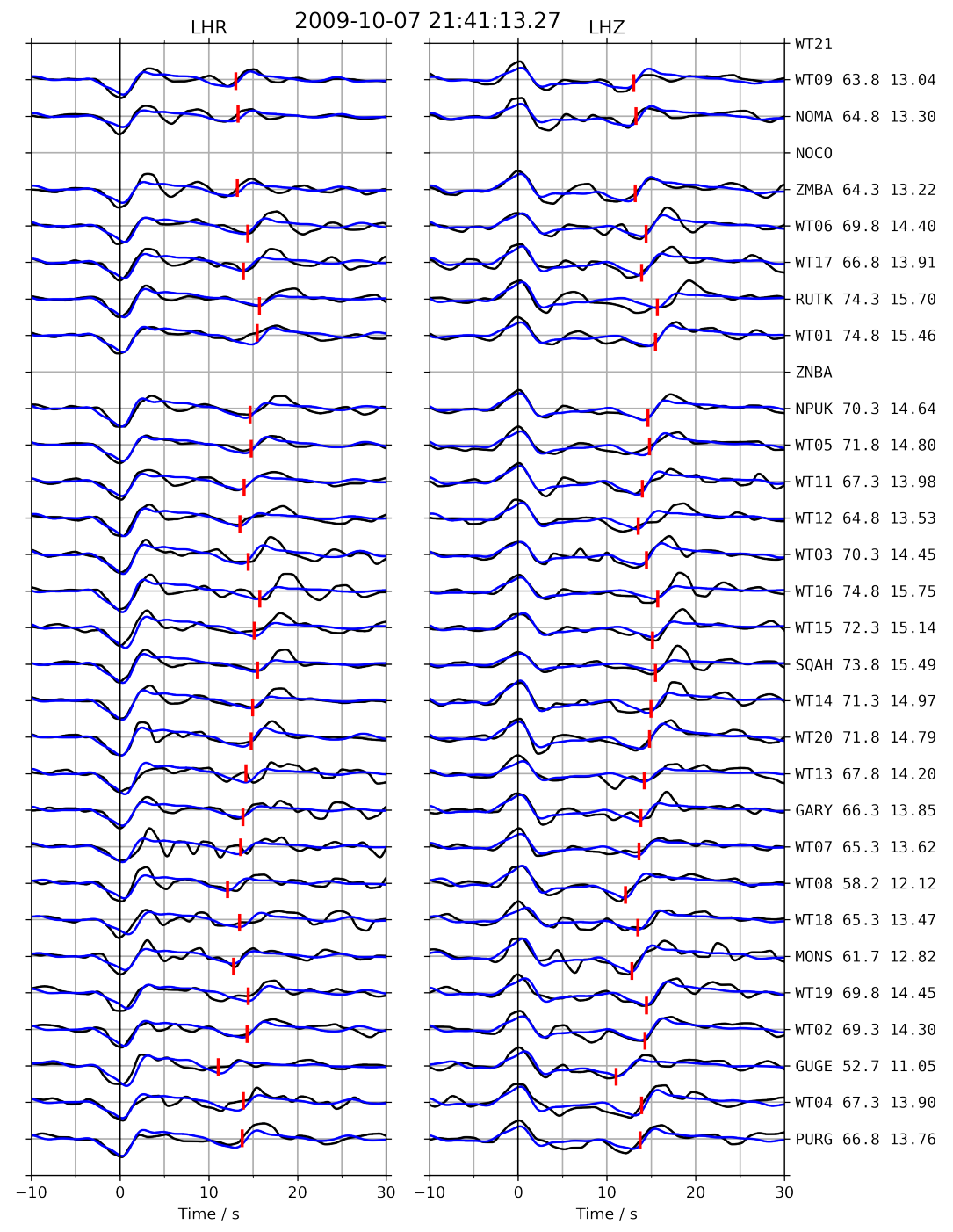

Supplementary Figure 10: See caption for supplementary figure 8 


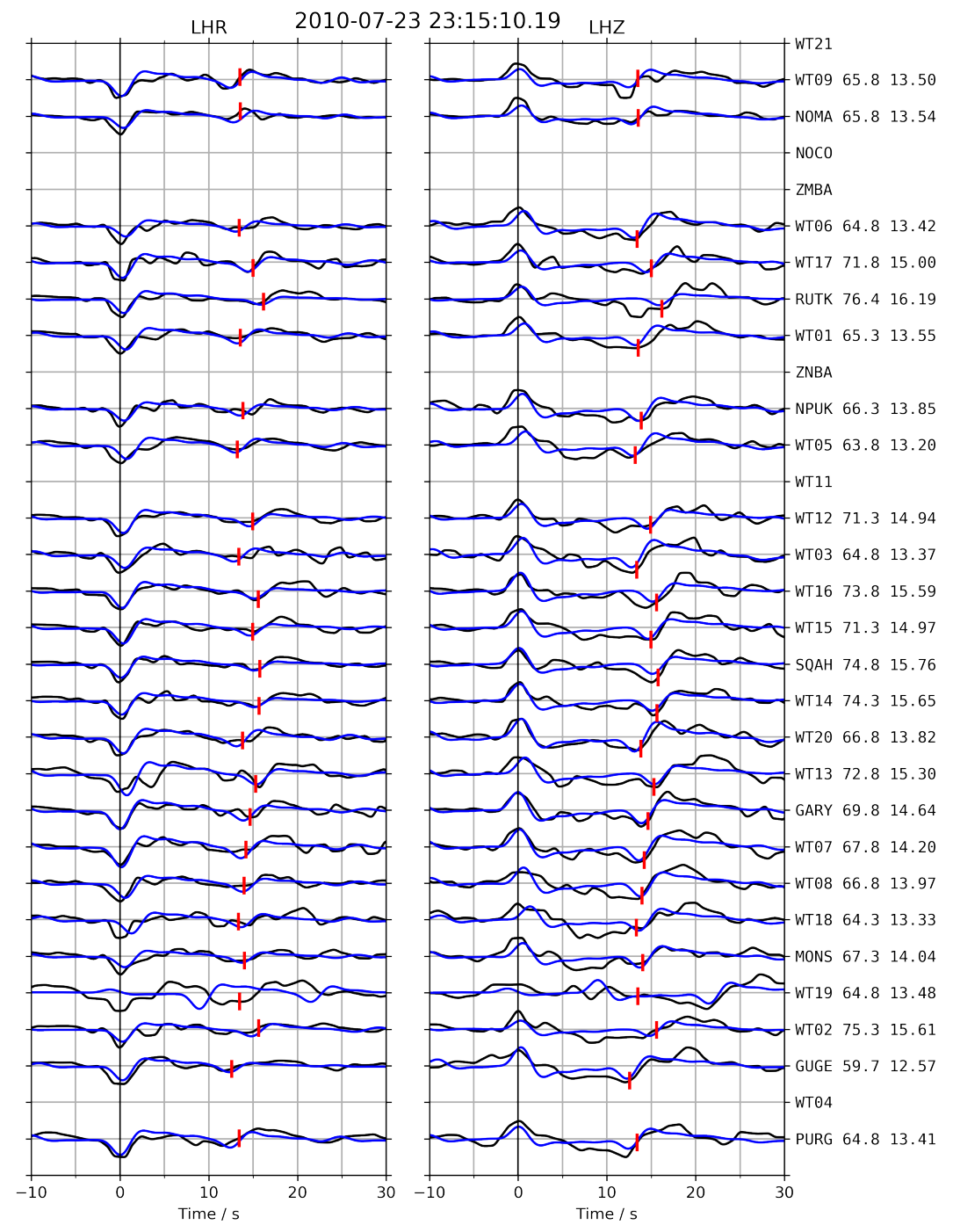

Supplementary Figure 11: See caption for supplementary figure 8 


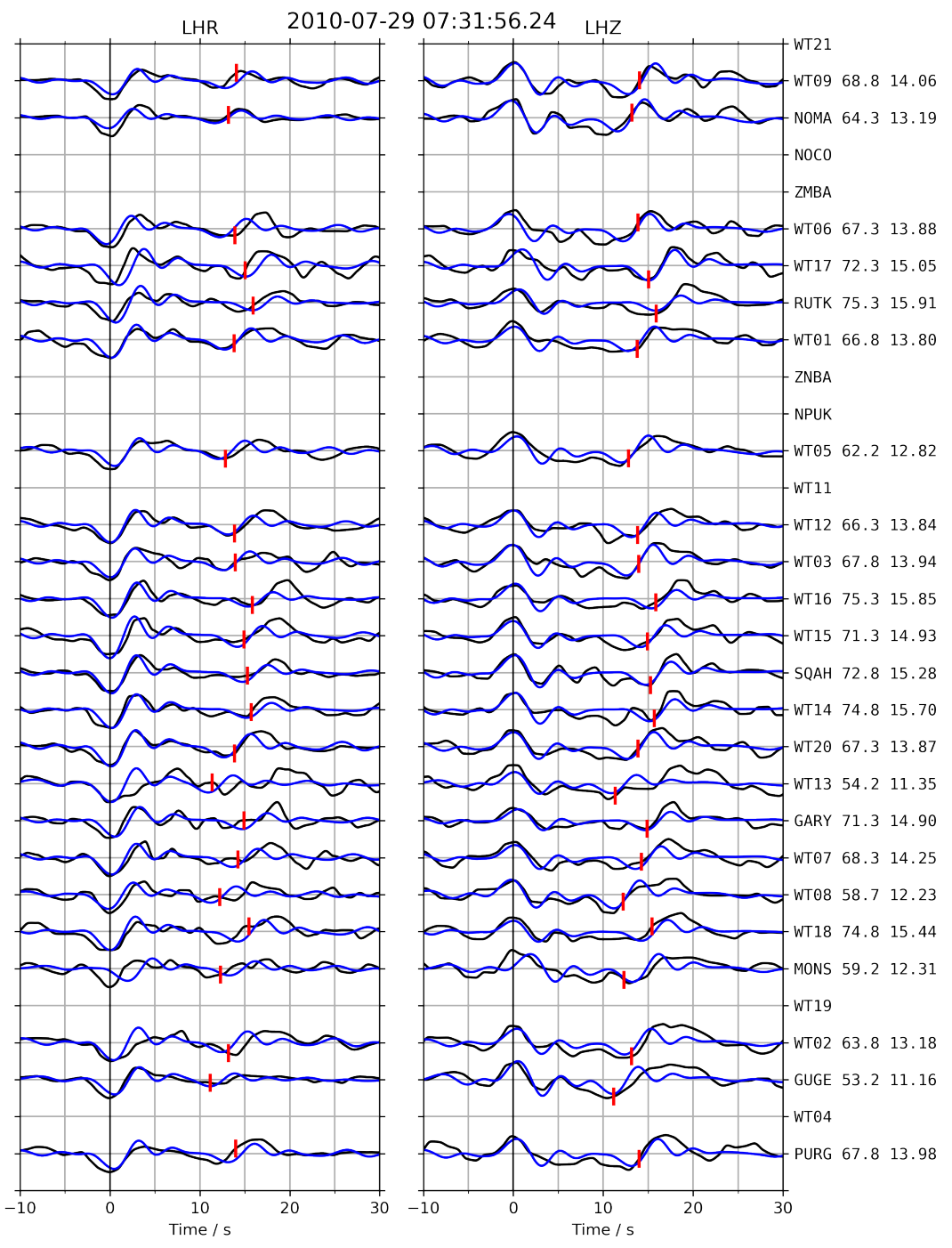

Supplementary Figure 12: See caption for supplementary figure 8 


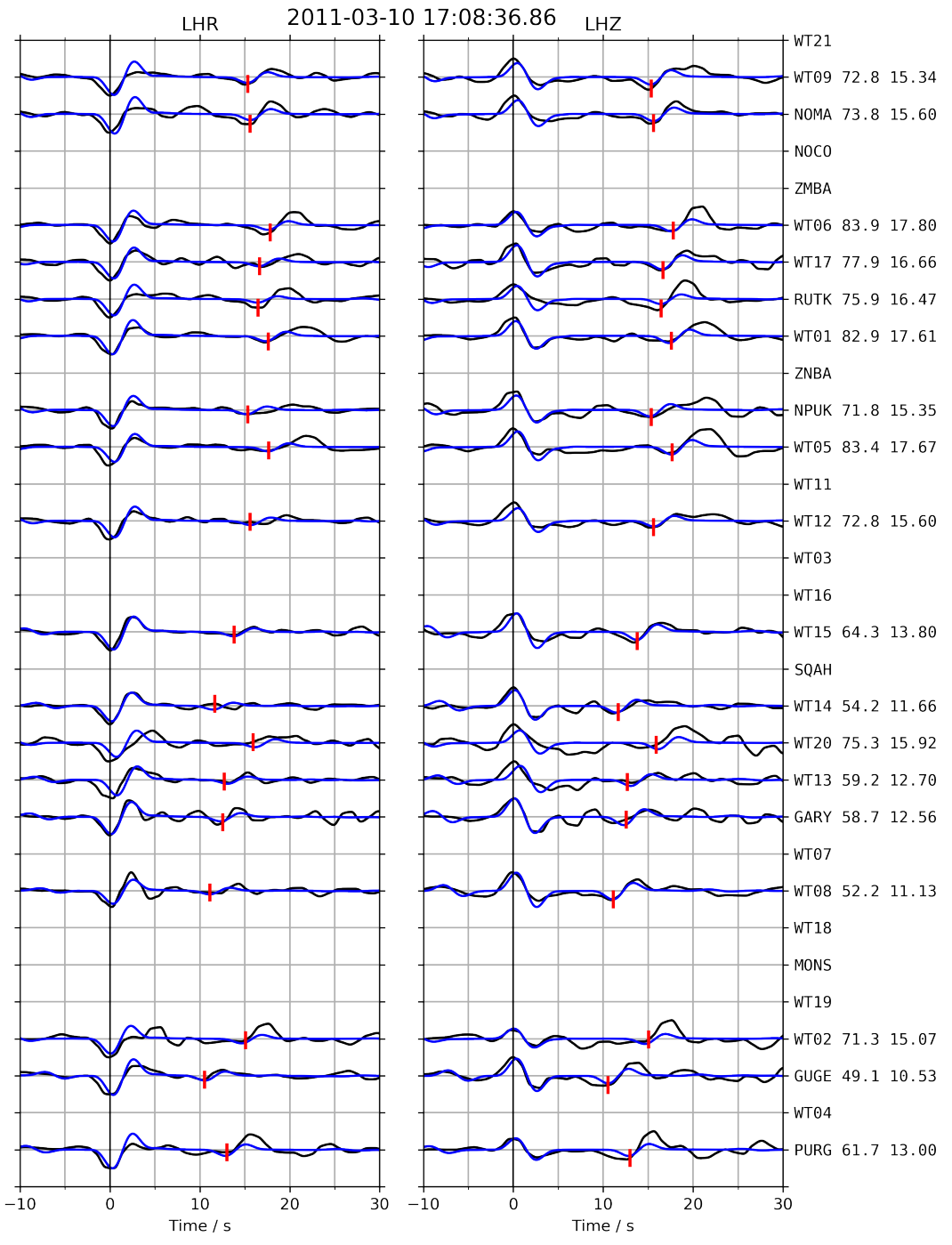

Supplementary Figure 13: See caption for supplementary figure 8 


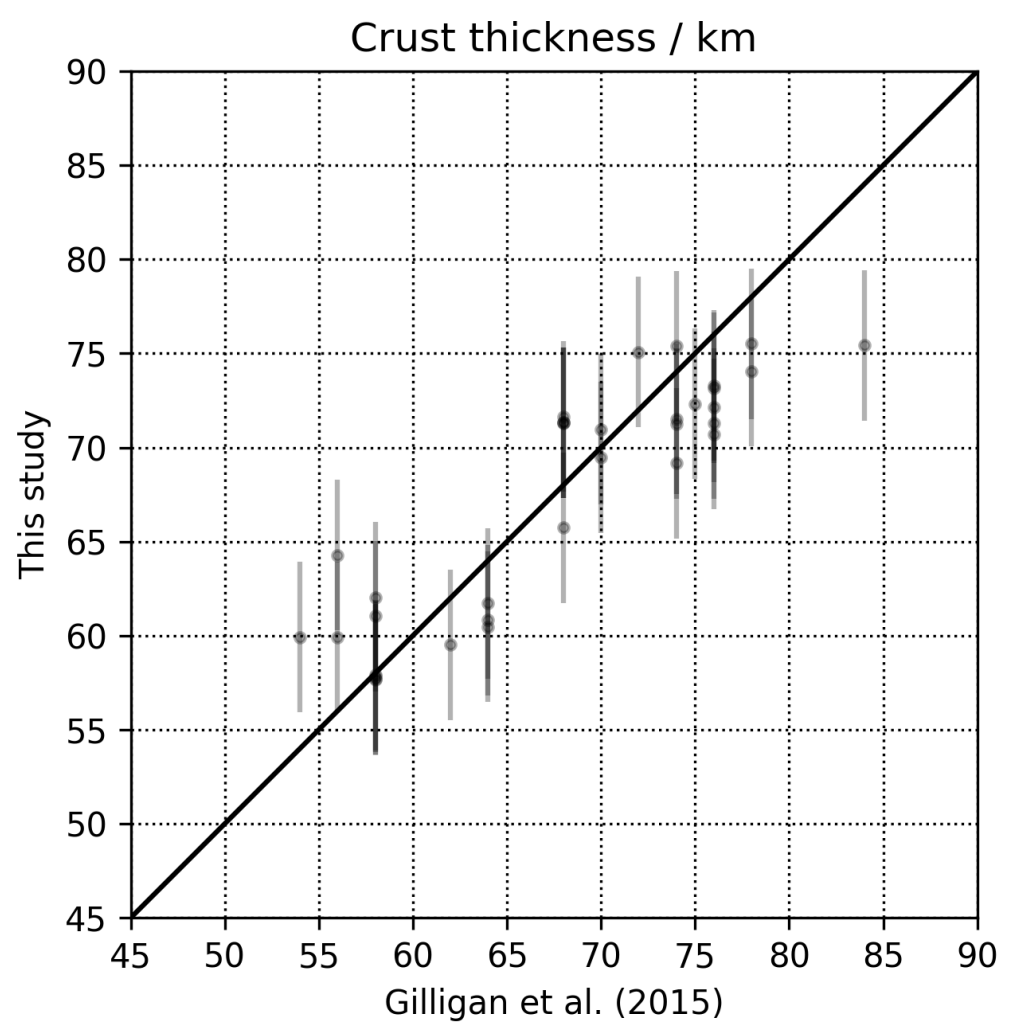

Supplementary Figure 14: Comparison of crust thickness estimates from this study and Gilligan et al. (2015). The one-standard deviation-uncertainty shown on our estimates is $4 \mathrm{~km}$, as discussed in the text. 


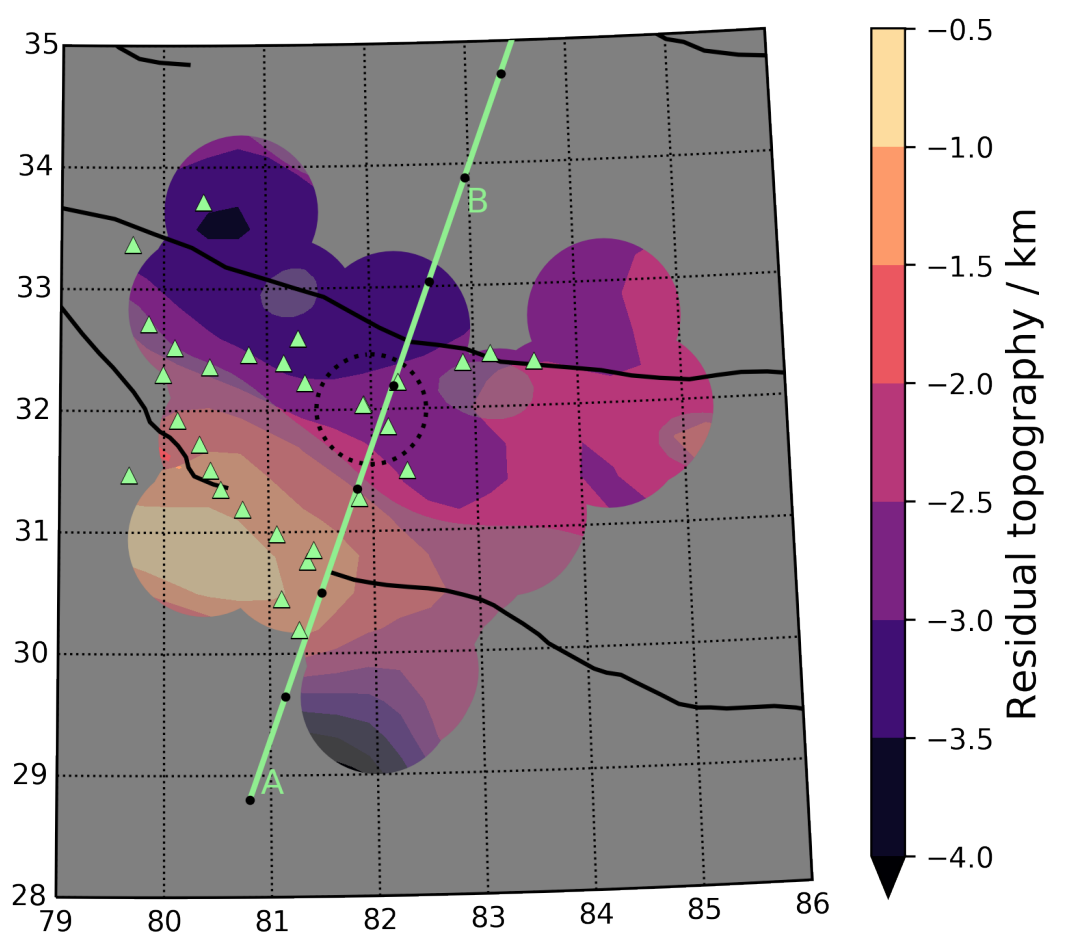

Supplementary Figure 15: A map of residual topography based on elevation (figure 11 and crust thickness (figure 8). The partially shaded region corresponds to areas where the magnitude of the free-air gravity anomaly is greater than $50 \mathrm{mGal}$ (supplementary figure 3 ) where the assumption of isostasy is unlikely to hold. Sutures, seismometers, the cross-section line and circled region of isostatic balance calculation are shown as in figure 1. 